Spring 6-12-2017

\title{
"It Just Weighs in the Back of Your Mind": Microaggressions in Science
}

Amy Anderson

DePaul University, aander98@depaul.edu

Follow this and additional works at: https://via.library.depaul.edu/csh_etd

Part of the Community Psychology Commons

\section{Recommended Citation}

Anderson, Amy, "'It Just Weighs in the Back of Your Mind": Microaggressions in Science" (2017). College of Science and Health Theses and Dissertations. 203.

https://via.library.depaul.edu/csh_etd/203

This Thesis is brought to you for free and open access by the College of Science and Health at Digital Commons@DePaul. It has been accepted for inclusion in College of Science and Health Theses and Dissertations by an authorized administrator of Digital Commons@DePaul. For more information, please contact digitalservices@depaul.edu. 
"It Just Weighs in the Back of Your Mind": Microaggressions in Science

\author{
A Thesis \\ Presented in \\ Partial Fulfillment of the \\ Requirements for the Degree of \\ Masters of Arts
}

By

Amy J. Anderson

June 1, 2017

Department of Psychology

College of Science and Health

DePaul University 
Thesis Committee

Bernadette Sánchez, Ph.D., Chairperson

Christine Reyna, Ph.D. 


\section{Acknowledgements}

I would like to thank my thesis chair, Bernadette Sánchez, and thesis committee member, Christine Reyna, for their continued support and guidance throughout this project. I would also like to thank the science support program that allowed us to collect data for this project. Lastly, I would like to express my deepest appreciation to my husband and family who supported me in this project and have always encouraged me to pursue my aspirations. 


\section{Biography}

Amy J. Anderson was born in Chicago, Illinois and raised in Little Rock, Arkansas where she graduated from Lutheran High School. Amy received a Bachelor of Arts in Psychology with honors from Oklahoma State University in 2012 and a Master of Science in Education from Johns Hopkins University in 2014. 


\section{Table of Contents}

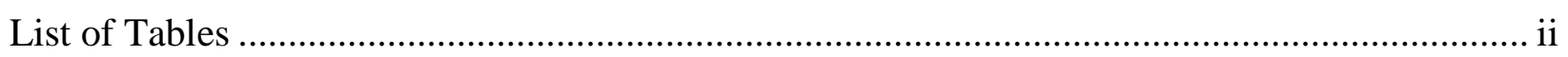

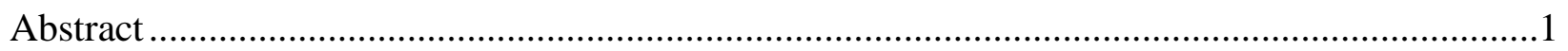

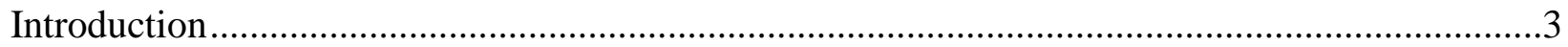

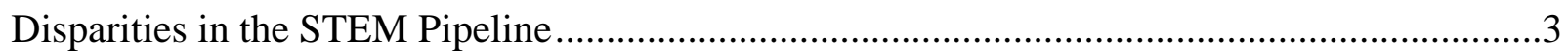

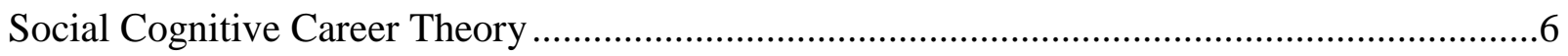

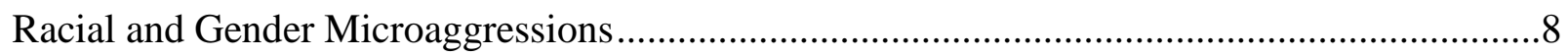

Microaggressions in the Sciences ..................................................................................12

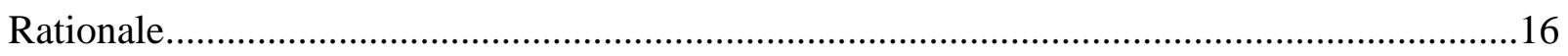

Research Questions ..............................................................................................19

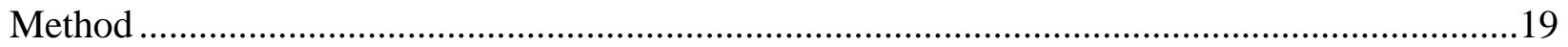

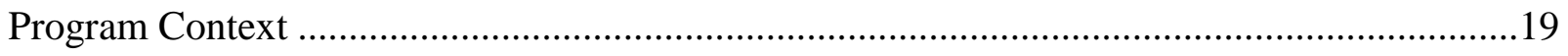

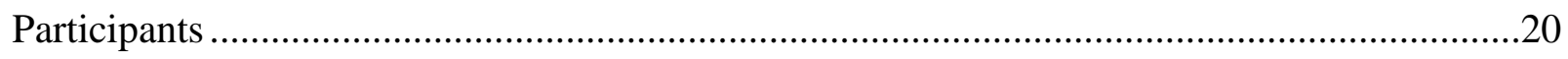

Procedure

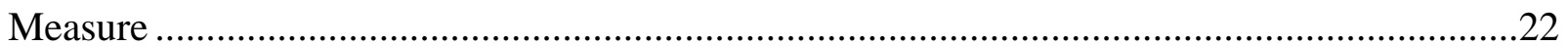

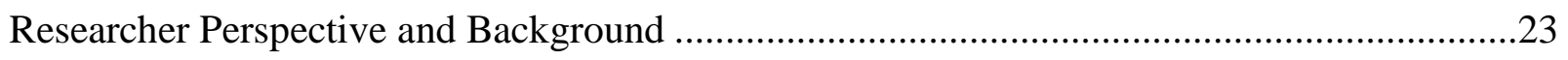

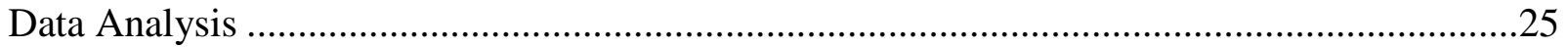

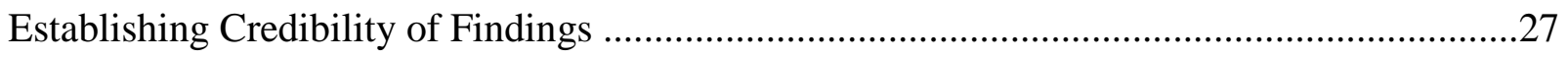

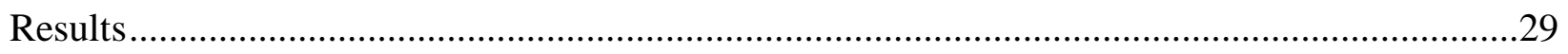

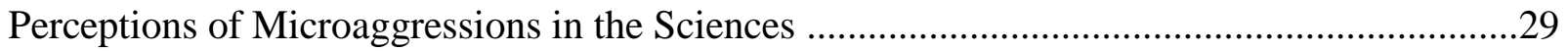

The Role of Microaggressions in Science Education and Careers.............................................48

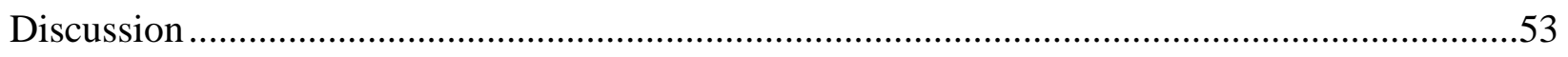

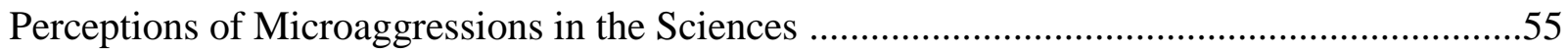

The Role of Microaggressions in Science Education and Careers...............................................56

Patterns of Microaggressions by Participant Identity ………..................................................58

Implications for Social Cognitive Career Theory …………...................................................60

Strengths and Limitations................................................................................................5

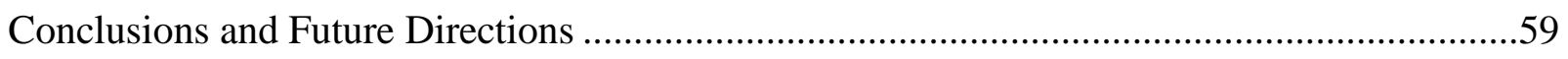

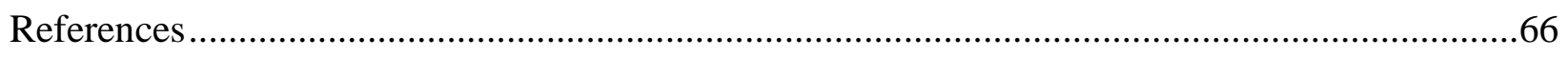

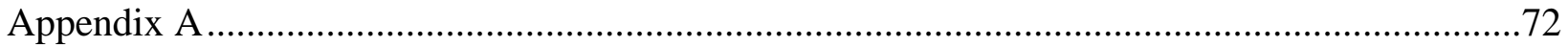




\section{List of Tables}

Table 1. Common Racial and Gender Microaggressions.......................................... 9

Table 2. Sample Demographics by Role in Program.................................................... 21

Table 3. Themes of Microaggressions and Patterns by Participant Group..................30

Table 4. Perceptions of Racial and Gender Microaggressions in the Sciences ..................31

Table 5. The Role of Microaggressions in Science Education and Careers......................48 


\begin{abstract}
Despite significant increases in academic degrees earned in recent decades, underrepresentation in the sciences still remains for women, African-Americans, Latina/os, and Native Americans (National Science Foundation, 2015). According to social cognitive career theory, academic and career development is impacted by contextual factors, such as environmental barriers (Lent, Brown, \& Hackett, 1994). Among previously examined factors, discrimination has been shown to be a barrier for individuals throughout their science academic and career development (Lent, Brown, \& Hackett, 2000). However, the impact of microaggressions, a subtler form of discrimination, requires further exploration for its potential influence on underrepresented groups in the sciences.

To fill the gap within the literature, the current study explored the role of racial and gender microaggressions on science academic and career choices. This study explored the racial and gender microaggressions that prevent diverse representation in the sciences, from the perspectives of youth, graduate students, and faculty who participate in a science support program for Latina/o youth. Three research questions were explored in this study: a) what are the perceived gender and racial/ethnic microaggressions in the sciences? b) what role do gender and racial microaggressions play in science education and careers? c) how do these perceptions of microaggressions vary by race/ethnicity, gender, and age? Qualitative one-on-one in-depth interviews were conducted with 11 youth, 11 graduate students, and 13 faculty members. Interview transcripts were analyzed using a modified grounded theory approach (Charmaz, 2006) and prior taxonomies of microaggressions were used to inform analysis (Sue et al., 2007; Capodilupo et al., 2010).

Perceptions of microaggressions fell into four overarching themes: 1) microinsults (including ascriptions of intelligence, assumptions of inferiority), 2) microinvalidations
\end{abstract}


(including invisibility, denial of racism and sexism, restrictive gender roles), 3) gendered microassaults (including hiring discrimination, sexual harassment), and 4) environmental invalidations (including lack of women scientists, lack of scientists of color, lack of role models). Participants reported several ways in which microaggressions impacted their science education career development, including: 1) detrimental to psychological well-being, 2) mobility across science contexts, 3) pressure to prove ability and competence, and 4) sense of social isolation. As suggested by SCCT, these findings support the role of microaggressions as a contextual factor negatively influencing career development. The current study has implications for increasing well-being, retention, and participation of women and underrepresented ethnic/racial groups in the sciences. 


\section{"It Just Weighs in the Back of Your Mind": Microaggressions in Science}

Innovation within science, technology, engineering, and math (STEM) is crucial to the United States' competitiveness in the global economy. STEM careers are expected to grow by 17\% between 2008 and 2018, outpacing non-STEM careers, which are expected to grow only 9.8\% (Economics and Statistics Administration, 2011). In order to fulfill growing demand, recruitment and retention of qualified individuals from all population groups are needed. Women currently account for approximately $50 \%$ of the U.S. population, and by 2060 it is expected that minority groups will comprise $57 \%$ of the total U.S. population (US Census Bureau, 2012). Despite representing a large share of the U.S. population, women and underrepresented racial/ethnic groups -- African-Americans, Latina/os, and Native Americans -- are not proportionally represented within STEM fields (National Science Foundation [NSF], 2015).

\section{Disparities in the STEM Pipeline}

National initiatives, such as President Obama's Educate to Innovate, have sought to address underrepresentation of women and racial minorities within STEM fields by targeting gaps in the "STEM pipeline" (The White House, 2009). The STEM pipeline is frequently used as a comparison to describe the path an individual takes through STEM career development. Beginning with elementary education and progressing through crucial milestones in high school, college, and the workforce, the pipeline illustrates which individuals abandon STEM career paths and those who persist (Cannady, Greenwald, \& Harris, 2014).

Examination of the gender disparities in STEM indicates that boys and girls participate at equal rates in early developmental stages of elementary and middle school (Hill, Corbett, \& St. Rose, 2010). However, exploration of high school math and science achievement data suggests that gender and racial disparities in the STEM pipeline widen during this critical time. In 2013, 
only $44 \%$ of U.S. high school students were considered prepared for college-level math, while $36 \%$ were prepared for college-level science (National Math and Science Initiative, 2013). In addition to this low achievement, racial disparities in advanced coursework pervade high schools. For example, $12 \%$ of Black students and 17\% of Latina/o students completed Algebra 1, whereas $48 \%$ of Asian students did so. Similar disparities occur in advanced coursework. While only $9 \%$ of Latina/o students and $10 \%$ of Black students took advanced Algebra or Calculus, $22 \%$ of White and $43 \%$ of Asian students completed these courses (National Math and Science Initiative, 2013). These statistics suggest that students receive vastly different educational opportunities that vary according to one's race. Because the opportunities to pursue STEM careers at a young age fail to materialize at a higher rate for underrepresented racial/ethnic groups and women, promotion within the STEM pipeline is negatively impacted.

As students' progress into college, disparities in science participation continue. Despite significant increases in academic degrees earned in STEM fields among women and underrepresented racial groups over the last several decades, the lack of representation for such groups has remained disproportionately low and inconsistent across varying disciplines (Hill et al., 2010; NSF, 2015). For example, over the past two decades women have maintained roughly $20 \%$ of all degrees earned in physics (NSF, 2015). While the number of doctoral degrees in physics earned by women has increased during this time, the number of earned bachelor's degrees has declined (NSF, 2015). Similarly, despite an increase in physical science degrees earned by underrepresented racial/ethnic groups since 1993, the growth over the last decade has been stagnant (NSF, 2015).

This disparity becomes even more striking when observing earned graduate degrees among women and underrepresented racial/ethnic groups. The rate of doctoral degrees earned by 
underrepresented minorities has shown little growth over the last decade, while advanced STEM degrees earned by women remain disproportionately low compared to males (Hill et al., 2010; NSF, 2015). For instance, Latina/os represent $17.6 \%$ of the general population (U.S. Census Bureau, 2015) but only four percent of graduate students within the sciences and four percent within the physical sciences (NSF, 2015). Overall, the data suggests that while the diversity of degrees earned in STEM fields has increased, progress remains slow and inconsistent.

The disparity in representation persists within the STEM workforce. Even in STEM fields where women are the majority (e.g. health related fields), they lack representation in more senior-level occupations, such as physicians and surgeons (NSF, 2015). Workforce statistics further demonstrate the lack of diversity among those within science and engineering occupations: white men 51\%, white women 20\%, Asian men 12\%, Asian women 5\%, Latino men $4 \%$, Latina women $2 \%$, Black men $3 \%$, Black women $2 \%$, other men $1 \%$, and other women $1 \%$ (NSF, 2015).

Similar trends occur within academic positions. Although representation among women and underrepresented minorities has increased over the last two decades, such groups constitute only a small portion of full professorships in the sciences. In 2013, women held approximately $25 \%$ of full-time, full professorships in science, engineering, and health, while underrepresented minorities held only $8 \%$ of such professorships (NSF, 2015).

The lack of participation of women and underrepresented racial groups in STEM is a cause for alarm and action. Aside from the economic implications, representational STEM disparities perpetuate unequal opportunities for women and racial minorities. Efforts to increase diversity must focus on both increasing numerical representation and examining the experiences that occur within the pipeline that shape individuals' involvement within the field. 


\section{Social Cognitive Career Theory}

Social cognitive career theory (SCCT) provides a lens for examining the gender and racial disparities in STEM fields. Originating from Albert Bandura's social cognitive theory (1986), SCCT explores the reciprocal relationships between an individual, the contextual environment, and an individual's experiences in pursuing academic and career interests (Lent, Brown, \& Hackett, 1994). SCCT focuses primarily on three components of career development: self-efficacy, outcome expectations, and goal-oriented actions. These components provide a framework for the processes in which individuals form and develop their interests, make choices surrounding those interests, and receive feedback on their performance (Lent et al., 1994). In addition, a key process within SCCT is the relationship of the individual to the environment. The promotion or deterrence from pursuing career goals occurs in the interaction between the individual, their experiences, and the environment (Lent et al., 1994). Specific environmental attributes can either support or undermine career development. These attributes are referred to as contextual factors.

Lent, Brown, and Hackett (2000) described contextual factors as both objective and subjective. For example, financial opportunities are objective factors that impact academic career development, whereas subjective factors are dependent upon individual interpretation (Lent et al., 2000). These factors can occur at different contextual distances from the individual. A distal, or more distant, factor could be the availability of role models for a particular career (Lent et al., 2000), whereas proximal factors could include experiences of discrimination. Moreover, contextual factors impact an individual throughout the career development process, whereas individuals who encounter less contextual barriers have stronger interest-goal-action relations 
than individuals with more perceived negative environmental factors (Lent et al., 1994; Lent et al., 2000).

One potentially influential contextual factor is racial and gender discrimination. Prior research has indicated that discrimination within education and the workplace can have negative impact on the recipient. In a meta-analysis of perceived workplace racial discrimination, Trina, Jayasinghe, and Pieper (2015) found that perceptions of racial discrimination were related to negative career outcomes, such as job attitudes and perception of job climate. Furthermore, perceptions of racial discrimination were also negatively related to the individual's physical and mental health. In addition to workplace discrimination, Rosenbloom and Way (2004) found that youth of color face discrimination within education. Findings from their study indicated that in addition to discrimination from peers, African-American youth experienced discrimination from adults. In both workplace and educational settings, the prior research indicates racial discrimination can have a negative impact on individuals.

Gender discrimination can also play a role as a contextual factor to educational and career development. Specifically, experiences of sexual harassment and gender discrimination within the workplace may have negative implications for those who experience them. Settles, Cortina, Malley, and Stewart (2006) examined experiences of sexual harassment and gender discrimination among women in science academia. The sample included 208 female, tenuretrack faculty the natural sciences (52\%) and social sciences (47\%). Analyses indicated that job satisfaction and feelings of influence at the university were negatively impacted by negative gender-related experiences (e.g. sexual harassment; Settles et al., 2006). Additionally, female faculty in the social sciences experienced fewer experiences of sexual harassment than female faculty in the natural sciences (Settles et al., 2006). 
Prior research on discrimination has provided a foundation for understanding how negative experiences related to race and gender may play a role in science pipeline disparities. Furthermore, while legislative reform over the last several decades has decreased explicit discrimination in education and the workplace, subtle discrimination remains widespread and often unmonitored (Dovidio \& Gaertner, 2000). The implications of subtle discrimination may have similar negative effects for the victim receiving the discrimination. However, this potentially relevant contextual factor has received inadequate attention in the STEM pipeline (Chen \& Soldner, 2013). The focus of the present study was to fill the gap in the SCCT literature by examining racial and gender microaggressions in the sciences as a contextual barrier influencing science career development.

\section{Racial and Gender Microaggressions}

A growing body of research has directed attention toward the microaggression taxonomy, which encompasses explicit and subtle forms of discrimination. The term microaggression was first devised by Pierce (1969) in relation to racial interactions that conveyed "subtle, stunning, often automatic, and non-verbal exchanges that are put-downs." This original work has been largely expanded over the last several years, and Sue (2010) asserts that microaggressions can occur in relation to any marginalized group identity (e.g., race, ethnicity, gender, ability, sexuality). Sue (2010) has defined microaggressions as “everyday verbal, and nonverbal, and environmental slights, snubs, or insults, whether intentional or unintentional, that communicate hostile, derogatory, or negative messages to target based solely upon their marginalized group membership" (pg. 3, 2010).

Sue et al. (2007) grouped racial microaggressions into three categories: microassaults, microinsults, and microinvalidations, and additional work by Capodilupo et al. (2010) led to the 
development of gender microaggression taxonomy. These taxonomies have been expanded upon in the literature but typically consists of a set of commonly occurring microaggressions represented in Table 1.

\section{Table 1}

Common Racial and Gender Microaggressions

\begin{tabular}{|c|c|c|}
\hline Microaggression $^{a}$ & Description $^{\mathrm{a}}$ & Type \\
\hline Alien in One's Own Land & Assumption that racial/ethnic minorities are foreign-born. & Microinvalidation \\
\hline Ascription of Intelligence & $\begin{array}{l}\text { Designating an amount of intelligence to an individual based on } \\
\text { their race or gender. }\end{array}$ & Microinsult \\
\hline Assumption of Inferiority & $\begin{array}{l}\text { Belief that women are less capable than men (e.g., physically, } \\
\text { academically). }\end{array}$ & Microinsult \\
\hline $\begin{array}{l}\text { Assumptions of Traditional } \\
\text { Gender Roles }\end{array}$ & $\begin{array}{l}\text { Instances when women are expected to follow gender roles or } \\
\text { stereotypes. }\end{array}$ & Microinsult \\
\hline Colorblind Ideology & Statements that communicate an individual does not see race. & Microinvalidation \\
\hline $\begin{array}{l}\text { Denial of Individual } \\
\text { Racism/Sexism }\end{array}$ & An individual's denial that they contribute to racism or sexism. & Microinvalidation \\
\hline Myth of Meritocracy & Belief that success is not impacted by race or gender. & Microinvalidation \\
\hline $\begin{array}{l}\text { Pathologizing Cultural } \\
\text { Values/Communication Styles }\end{array}$ & $\begin{array}{l}\text { Belief that the values and communication styles of racial } \\
\text { minority groups are lesser. }\end{array}$ & Microinsult \\
\hline Racial/Sexist Derogation & Intentional racist epithets or sexist statements (e.g. catcalling) & Microassault \\
\hline Second-class Citizen & $\begin{array}{l}\text { An individual is treated as less important within a group because } \\
\text { of their race or gender. }\end{array}$ & Microinsult \\
\hline Sexual Objectification & When a woman's worth is reduced to sexuality. & Microinsult \\
\hline Use of Sexist Language & $\begin{array}{l}\text { Statements that exclude, degrade, or perpetuate negative } \\
\text { stereotypes about women. }\end{array}$ & Microinsult \\
\hline
\end{tabular}

a. (Capodilupo et al., 2010; Sue et al., 2007)

Microassaults are deliberate and conscious behaviors or comments that represent bias toward a minority group member based on their group membership (Sue, 2010). For example, racist epithets or catcalling women are explicit forms of microassaults (Capodilupo et al., 2010; Sue, 2010). Microinsults include behaviors or verbal comments that demean an individual based on their identity group (Sue et al., 2007). Sue (2010) describes that, unlike microassaults, microinsults are often unconscious comments or behaviors that "communicate rudeness, 
insensitivity, slights, and insults that demean a person's racial, gender, sexual orientation, or group identity and heritage" (pg. 9). Like microinsults, microinvalidations also frequently occur unconsciously. These interactions invalidate the individual's reality or experiences as a member of their marginalized group (Sue, 2010). The three forms of microaggressions can all occur on the systematic or ecological level and are referred to as environmental invalidations (Sue et al., 2007).

Previous investigations have found that microaggressions occur in a variety of settings and are related to negative outcomes. For example, Nadal (2011) found that experiencing racial microaggressions within education and the workplace also significantly predicted lower selfesteem. In a separate study, Nadal, Wong, Griffin, Davidoff, and Sriken (2014) examined the role of racial microaggressions in 225 racially/ethnically diverse college students' (72\% female, $28 \%$ male) self-esteem. Analyses demonstrated significant differences in racial microaggressions between racial groups. For example, White participants reported experiencing significantly fewer racial microaggressions than all other groups (i.e., Latina/os, African Americans, Asian Americans Islander, Multiracial), and analyses indicated that overall racial microaggression scores predicted self-esteem (Nadal et al., 2014).

Similar to racial microaggressions, gendered microaggressions within the careers and workplace settings may also play a role in preventing diverse representation the sciences. Capodilupo et al. (2010) developed themes of gendered microaggressions derived from the taxonomy of racial microaggressions that included: sexual objectification, assumptions of inferiority, assumptions of traditional gender roles, use of sexist language, and denial of individual sexism. Several of these gendered microaggressions are relevant to the workplace experience. For example, a woman might experience assumptions of traditional gender roles by 
being assigned to take on housekeeping or domestic duties in the office, whereas male colleagues are not held to this expectation (Capodilupo et al., 2010; Nadal, 2009). Women may also experience assumptions of inferiority in the workplace. For example, women may be told that they are too emotional, implying that they are less able or competent (Nadal, 2009; Sue \& Capodilupo, 2008). However, in review of the literature, Nadal (2009) noted that few studies have empirically examined gender microaggressions. These gendered experiences may create a negative climate and have implications for job satisfaction and require further examination.

Researchers have also provided evidence that microaggressions uniquely occur at the intersections of marginalized identities, such as gender and ethnicity. In a qualitative study of 66 Chicana and Chicano, graduate and postdoctoral students, Solórzano (1999) found experiences of microaggressions were related to feelings of disconnection to the university community. Furthermore, Chicana scholars described added experiences of microaggressions at the intersection of their racial and gender identities. Similar findings were illustrated by Nadal, Mazzula, Rivera, and Fujii-Doe (2014) in an examination of the role of demographic and sociopolitical factors in microaggressions perceived by 311 Latina/o participants (77\% female; Dominican (28.6\%), Puerto Rican (23.3\%), Mexican (9.6\%)) among a sample of primarily college students with the remainder from the community. The results indicated significant differences in the experiences of microaggressions by gender, age, education level, and birthplace, wherein Latina women were more likely than Latino men to have experienced microaggressions within education and the workforce (Nadal et al., 2014). The findings suggest that the intersection of racial and gender identities may have an impact on the experiences of Latina women in their educational and career development. 
Existing taxonomies of microaggressions and prior research provides a useful framework in examining the experiences of marginalized individuals who are underrepresented within the STEM pipeline. These taxonomies have been expanded upon throughout the literature and can be applied to a variety of settings. This framework of subtle discrimination will be used in the current study to examine the experiences of marginalized individuals who are underrepresented within the STEM education and workforce.

\section{Microaggressions in the Sciences}

Although previous research has explored microaggressions in a variety of settings (e.g., education, careers), a limited amount of investigations have explicitly explored microaggressions within science settings. In a qualitative investigation, Barthelemy, McCormick and Henderson (2016) explored gender microaggressions among 21 women graduate students in physics. Using Sue and Capodilupo's (2008) framework of gender microaggressions as a grounding for their study, they found similar themes to the existing taxonomy. Their findings suggested that many women experienced gender microaggressions in their pursuit of a graduate degree in physics. A sample of the prominent themes includes: assumptions of inferiority, invisibility and restrictive gender roles. The study provided additional empirical for the existing taxonomy of gender microaggressions (Sue \& Capodilupo, 2008).

The current literature on environmental invalidations in science, or microaggressions occurring at the structural level, is also limited. Lester et al. (2016) conducted an ethnographic case study in which they conducted observations of technology courses and qualitative interviews $(n=9)$ with women students at a community college. Analyses indicated that the physical structure and instruction communication styles encouraged a competitive learning environment and often distanced or isolated women from the setting. Although their findings 
indicated gendered microinsults and microinvalidations, such as using the word "girls" rather than "women" while men was used, they did not find microassaults (Lester et al., 2016). The findings suggest the important role of gendered environmental invalidations in women's experiences within science classrooms. However additional research is needed that examines other aspects of the science environment beyond the classroom setting (e.g., departments). In addition to explorations of gender microaggressions, some research has explicitly examined racial microaggressions within STEM settings. Brown et al. (2016) conducted a mixed-method investigation of African-American scientists' pursuit through the science pipeline. Specifically, they explored the role of microaggressions in alignment to science communities among African-American graduate students and scientists across STEM disciplines. Among their findings was a key difference between students and scientists' perceptions of alignment to the science community, wherein students felt more connection to the science community as well as fewer perceived microaggressions compared to scientists. The authors also found that increased racial pride was related to perceptions of more microaggressions and misalignment with the science community (Brown et al., 2016). The findings suggest an interesting relationship between the perceived connection to the science community and experiences of racial microaggressions.

As with prior research on experiences of microaggressions more broadly, women of color in the sciences may have unique experiences of microaggressions at the intersection of their racial and gender identity. In a phenomenological study, Alexander and Hermann (2015) examined the experiences of eight African-American female graduate students in STEM at a predominately White university (PWU). Three themes of racial and gender microaggressions emerged within the data: racial stereotyping, ascription of intelligence, and feeling invisible. 
Participants perceived white classmates making racial stereotypes about the participants' racial group, which is a type of microinsult. Such stereotypes made it difficult for participants to feel comfortable around White classmates (Alexander \& Hermann, 2015). Participants discussed experiences of ascription of intelligence, another common microinsult; specifically, participants described having to prove their intelligence within their university's STEM community and receiving messages that they were not intellectually prepared to study engineering (Alexander \& Hermann, 2015). These microaggressions had a negative impact on students' feelings of belonging and importance within the university (Alexander \& Hermann, 2015).

In addition to experiences of microaggressions as graduate students, prior research indicates faculty may experience unique microaggressions at their universities. Guzman, Trevino, Lubuguin, and Aryan (2010) found that racial minorities not only face microaggressions throughout their educational development, but may also face microaggressions in the academic tenure process. One such experience is the assumption that racial minority members are experts of their racial group. This assumption often leads to participation requests for university service related to race that is disproportionally asked of scholars of color in comparison to White peers (Guzman et al., 2010). Similarly, Pittman (2012) found similar results in a case study of experiences of race among 14 African-American faculty members ( 7 male, 7 female) in the social sciences, humanities and natural sciences at a PWU. A major theme in the interview transcripts was the occurrence of microinvalidations within their interactions with White colleagues (Pittman, 2012). For example, White colleagues asked questions that conveyed that African-American faculty knew about everything pertaining to the African-American community (Pittman, 2012). An additional theme was the prevalence of microinsults (36\%) occurring from interactions with White students, such as instances when Whites students asked an African- 
American faculty member if they were a student employee rather than a faculty member. Lastly, African-American faculty described being frequently asked to engage in university service related to race (e.g., committees).

Although research of microaggressions in higher education has been previously explored, research on the perceptions from high school students in science remains limited. In an investigation of high school students, Grossman and Proche (2013) conducted a mixed-methods study of perceived gender and racial/ethnic barriers to STEM education and careers. In the study, 53 students were interviewed (56\% female; 26\% Asian, 16\% Black, 11\% Latina/o, 30\% White, 4\% Other, $13 \%$ Biracial). Microaggressions and responses to microaggressions emerged as prevalent themes within the interviews (Grossman \& Proche, 2013). Among the themes, female and underrepresented minority students were more likely than male students or students from overrepresented groups to identify microaggressions (Grossman \& Proche, 2013). Forty-five percent of participants mentioned microassaults related to power dynamics of gender or race/ethnicity in STEM. Examples of microassaults included discrimination based on gender and race, or systemic barriers of resource disparities (Grossman \& Proche, 2013). Sixty-six percent of participants mentioned microinsults related to STEM, and examples included experiences of strict gender role stereotyping or assumptions of inferiority among minority students. Specific examples of gender role stereotyping included the notion that women were less interested in science or messages that childcare was more suitable. Racial minority students experienced assumptions of inferiority, and their performance capabilities were seen as lower than those of other racial groups (e.g. white, Asians; Grossman \& Proche, 2013).

Even though many students experienced microaggressions, some students expressed that they did not perceive barriers within STEM (34\%) or recognized a progression of equality in 
STEM (36\%; Grossman \& Proche, 2013). Given that barriers along race and gender lines occur early in the STEM pipeline, this research has important implications for increasing diversity within the STEM fields. Although many students perceive the STEM climate as improving or altogether free of barriers, many students continue to experience negative interactions through subtle or overt acts of discrimination. Similar to prior research, these perceptions varied by gender and racial groups.

Overall, prior research indicates that racial and gender microaggressions within the sciences can negatively affect scientists who experience them (Grossman \& Proche, 2013; P Brown et al., 2016; Pittman, 2012). Specifically, racial microaggressions in the sciences may negatively influence feelings of importance within the setting (Alexander \& Hermann, 2015), and may occur throughout a person's educational career (Brown et al., 2016). Furthermore, women in the sciences may experience gender microaggressions about their science ability and worth within the setting (Barthelemy et al., 2016) and women of color may often incur added burden when experiencing microaggressions at the intersection of their racial and gender identities (Nadal et al., 2014). In sum, the influence of racial and gender microaggressions may be of importance in science settings, wherein women and ethnic minorities are more likely to experience these educational microaggressions than their male and white counterparts, respectively (Grossman \& Proche, 2013).

\section{Rationale}

Although women and underrepresented racial groups -- individuals from AfricanAmerican, Latina/o, and Native American backgrounds -- make up a large portion of the U.S. population, they comprise only a small portion of the STEM workforce (NSF, 2015; U.S. Census 
Bureau, 2012). This underrepresentation is alarming and requires attention in order to increase economic innovation within the U.S. and provide equal opportunity to all individuals.

SCCT is a theoretical framework for understanding how individuals make academic and career related decisions (e.g. STEM education and careers). In particular, SCCT has explicated how environmental factors impact these decisions from formation of the academic interest to achievement within the respective field (Lent et al., 1994). Such factors include barriers toward a particular academic and career goal, whereas individuals who experience fewer environmental barriers will have more positive experiences with their academic interests and attainment of related interest (Lent et al., 1994). Despite the well-established understanding of the role of explicit barriers (e.g., discriminatory policies; Lent et al., 2000) and the negative impact of discrimination on careers (Trina et al., 2015), the examination of microaggressions as a contextual barrier throughout science education and career development requires further examination.

Discrimination in the form of racial and gender microaggressions poses several problems. Discrimination has negative implications for fulfilling growing STEM positions with the U.S. economy. Moreover, it also diminishes the well-being and opportunities for diverse groups of individuals within the sciences. Prior research has suggested that racial microaggressions in educational settings play a role in individuals' sense of belonging and self-esteem (Alexander \& Hermann, 2015; Nadal et al., 2014). Additionally, microaggressions within STEM settings may send negative messages about one's science ability (Barthelemy et al., 2016) or may be related to a lack of a sense of connection to the science community (Brown et al, 2016).

Although research has recently begun to examine the role of gender and racial microaggressions within science education and careers, several gaps exist. First, only one known 
study (Grossman \& Proche, 2013) has explored perceptions of racial and gender microaggressions in STEM among high school students. This is a necessary area of exploration as students are making career-related decisions and developing future career interests. Second, environmental invalidations, as described in existing microaggression taxonomies (Sue, 2010; Sue \& Capodilupo, 2010) requires further empirical investigation. While evidence suggests the environment plays an important role in science experiences (Lester et al., 2016), the environmental invalidations as racial and gender microaggressions have yet to be explored explicitly related to science settings within the existing literature. Lastly, few studies have examined implications of gender microaggressions within the sciences on pursuit through the science pipeline. While the literature on gender microaggressions in these settings is emerging (Alexander \& Hermann, 2015; Barthelemy, 2016; Brown et al, 2016), it predominately focuses on the experiences of graduate students in STEM settings. Furthering the understanding of gender microaggressions in science academic and career development is useful as women continue to make up the majority of undergraduate degrees yet they remain underrepresented in the science fields compared to male counterparts (White House, 2014; National Science Foundation, 2015).

The described gaps are significant limitations within the microaggression literature given the pressing need to increase representation and the well-being of underrepresented groups in science fields (Chen \& Soldner, 2013). The current study filled these gaps through a unique examination of the role of microaggressions as a contextual barrier at different milestones of individuals' career development within the sciences. Guided by SCCT, this investigation provided further examination to the perceptions of microaggressions held by high school and college students who are interested in pursuing higher education and careers in science. 
Additionally, the current study adds to the literature by investigating environmental invalidations and gender microaggressions in science settings.

In the present study, participants within a science support program for Latino/a youth provided understanding from varying perspectives and phases of career development. Specifically, interviews of various stakeholders who are involved in a science support program and are in different points in the STEM pipeline, including faculty members, graduate students, college students and high school students, were examined. This exploration provided further understanding of the experiences impacting individuals' career selection of, and retention within the sciences. Moreover, such an examination has the opportunity to promote the well-being of such individuals in the sciences and expand the perspectives contributing to the body of science knowledge. This study examined racial and gender microaggressions within the sciences, their role in science education and careers, and the variation of these experiences across multiple identities.

\section{Research Questions}

a) What are the perceived gender and racial/ethnic microaggressions in the sciences?

b) What role do gender and racial microaggressions play in science education and careers?

c) How do these perceptions of microaggressions vary by race/ethnicity, gender, and age?

\section{Method}

\section{Program Context}

The current study was a part of a larger evaluation of the STEMulate program ${ }^{1}$, a summer science research support program at a Midwestern university. The evaluation was conducted in the fifth year (2015) of the program's existence. The overall purpose of the science program is to

\footnotetext{
${ }^{1}$ Pseudonym is used to describe the program to protect the identity of participants.
} 
strengthen the pipeline of Latinos/as in the sciences. This is a long-term, paid science research program where Latina/o students are selected to participate during the summer after their junior year of high school and return each summer until they graduate from college. There were 15 students in the program with roughly 3-4 high school juniors admitted each year. The program runs for approximately 10 weeks each summer, and students who participate in the program are employed to work in research labs. During the program, students are assigned to work under a faculty advisor and are paired with a graduate student mentor. In addition to research in the lab, students take math and science coursework, attend field trips to local universities, and prepare science presentations at the end of the summer.

\section{Participants}

Given the small size of the program, all current and former STEMulate students, graduate students mentors, and faculty advisors from the science program were invited to participate in the study. Thus, a total of 55 individuals were targeted to for the study ( 3 staff, 9 current graduate student mentors, five former graduate student mentors, 18 faculty advisors, 15 students, and five former program participants). Seventy-one percent $(N=39)$ of those recruited enrolled in the study. There was one graduate student mentor and three staff members who were excluded from the current study because the questions related to race and gender experiences in the interview protocol was not applied to their interview.

The current study's sample consisted of 35 participants and the demographic information is listed in Table 2. There were 11 STEMulate participants (31\%), 11 graduate students (31\%), and 13 faculty advisors (37\%). The participants in the study included 21 male (60\%) and 14 female $(40 \%)$ participants, with ages ranging from $16-64$ years old $(M=33.38, S D=15.55)$. The participants varied in level of educational attainment: 11 high school/below bachelor's degree, 5 
bachelor's degrees in the sciences, 4 master's degrees, and 15 doctoral degrees. Participants in the study represented a variety of ethnic backgrounds and were able to report multiple race/ethnicities. Responses include 14 Latino/a-Mexican (40\%), 3 Asian/Pacific Islander (9\%), 19 Caucasian (54\%), and one Other (3\%).

Table 2

Sample Demographics by Role in Program

\begin{tabular}{lccc}
\multicolumn{1}{c}{$(\mathrm{N}=35)$} & $\begin{array}{c}\text { STEMulate } \\
\text { Students }\end{array}$ & $\begin{array}{c}\text { Graduate } \\
\text { Students }\end{array}$ & Faculty \\
\hline Age in Years $(M)$ & 18 & 29 & 52 \\
Gender & & & \\
$\quad$ Women & $5(46 \%)$ & $5(42 \%)$ & $4(31 \%)$ \\
$\quad$ Men & $6(56 \%)$ & $7(58 \%)$ & $9(69 \%)$ \\
Race/Ethnicity & & & \\
$\quad$ Latina/o & $11(100 \%)$ & 1 & $1(8 \%)$ \\
Asian/Pacific Islander & - & $2(16.7 \%)$ & $1(8 \%)$ \\
White & - & $9(67 \%)$ & $11(84 \%)$ \\
$\quad$ Indian & - & $1(8 \%)$ & - \\
$\quad$ Multiracial & - & $1(8 \%)$ & - \\
\hline
\end{tabular}

${ }^{a}$ Participants could report more than one ethnicity.

\section{Procedure}

Informed consent was conducted with all participants and parental permission was obtained for youth participants under 18 in either Spanish or English. The consent forms contained information regarding the purpose of the study, the potential risks and benefits of voluntary participation, study procedures, and the researcher's contact information for additional questions.

One-on-one in depth interviews were conducted using a semi-structured format. A team of five researchers conducted the interviews over a period of five months (June through October). The researchers represented various gender and racial backgrounds: one Latina faculty, three white female graduate students, and one Latino graduate student. The interviews were conducted at the university where the program was held in private offices and conference rooms. 
In order to interview former program participants, several interviews were conducted over the phone due to their geographic location. The interviews ranged from 30 to 150 minutes in length. Each interview was digitally recorded and transcribed. Following each interview, participants completed a survey to gather demographic and educational information. Participants were compensated with a $\$ 25$ gift card to Target for their participation.

\section{Measure}

The interview protocol (see Appendix A) sought to understand participants' experiences within the science research program as well as their broader experiences with race, ethnicity and gender in the sciences. The interview protocol was developed based on social cognitive career theory (Lent, 1994) and examined the development of an individual's career interests, their outcome expectations, and the contextual factors related to race and gender in the sciences.

The focus of the current study is the section of the interview protocol about participants' perceptions of race, ethnicity and gender within the sciences. This section was prefaced by stating:

the National Science Foundation has suggested that it is important to increase the number of women and underrepresented racial/ethnic minority groups in science. We're interested in this topic as well, so I'm going to ask you some questions about the roles of gender and race/ethnicity in science.

Following this introduction, participants were asked how they identify in terms of gender, race, and ethnicity. This answer was then used throughout the rest of the interview protocol to frame the questions.

Participants were asked to describe how this identity has impacted their experiences within their science education and careers. Attention was given to both experiences of race and gender. Next, participants were asked about perceptions of barriers along the lines of gender. They were asked about what barriers may be faced by both males and females within the 
sciences. Following these questions, participants were asked about barriers within the sciences for racial/ethnic minorities. Given the context of the program, student participants were asked specifically about barriers for Latinas/os in the sciences. Graduate students and faculty were more broadly asked about barriers for racial/ethnic minority groups.

The interview protocol also addressed the alignment between science related expectations and those related to race and gender. Participants were asked about expectations held by those closest to them, such as family and friends, and the alignment of those expectations to their pursuit of education or career in the sciences. Additionally, participants were asked if they had ever experienced explicit discrimination within the sciences. Lastly, given the focus of the program, participants were asked what advice they would give to Latina/o students interested in pursuing the sciences.

\section{Researcher Perspective and Background}

My interest in diversity within the sciences has developed through personal and professional experiences. I am a white woman, born in Chicago, Illinois but have spent the majority of my upbringing living in Little Rock, Arkansas. In Arkansas, my parents enrolled me in a small, predominately white parochial school, which I attended from elementary through high school. The consistent support from the same network of friends and teachers provided a strong educational foundation to develop a love for learning. During this time, I had access to excellent teachers, academic resources, and extracurricular opportunities -- a privilege that directly impacted my academic future.

Throughout my high school education, I was a high performing student, and particularly interested in the sciences. During this time an encouraging mentor provided me with opportunities for career exploration and science research at two local universities. After 
participating in summer science research and a science career exploration program, I selected biology as my undergraduate major at Oklahoma State University. In a required general education chemistry course, I was one of 200 students with little contact with the professor or engagement beyond lecture. Despite prior success in high school science and AP coursework, I received a below average course grade and felt disconnected from the content. This negative experience reinforced a change in my major to psychology, which I perceived to have more realworld applications. I recognize this experience as my own individual experience along the STEM pipeline.

In addition to studying psychology, I earned an undergraduate minor in women and gender studies. Within my women and gender studies coursework, I developed a foundation for the feminist perspective through which I currently approach life and my work. In addition to feminism, I began learning about the intersections of race and gender. During this time, I formed an understanding of the intersections of my own identity and how these have benefited me. As a white woman, I have been afforded many unearned privileges throughout my life and education. While I have had negative interactions and expectations based on my gender, I have been privileged as a white individual. Such privileges include the absence of discrimination based on racial group membership and access to an excellent education. This learning experience became the foundation for my feminist perspective and interest in equality within education.

With a sparked interest in educational equality, I accepted a position teaching in Baltimore City, Maryland following graduation. During this time, I worked as a middle school math teacher at an urban, STEM charter school. The school served student's from primarily lowincome backgrounds and the student population was predominantly African-American (81\% African-American, $8 \%$ Hispanic/Latino, and 8\% White). Before stepping into the classroom, I 
was trained to teach using an innovative, computer-based math curriculum that was aligned to the Common Core. Upon entering my school, I soon learned that the lack of resources would prohibit adequate implementation of the curriculum. Despite boasting a STEM mission and name, the school had little to no technology. Coupled with deteriorating facilities and understaffing, effectively implementing the curriculum and meeting students' needs was extremely difficult.

During my teaching experience, I saw firsthand how systemic inequity in public schools negatively impact student interest in STEM disciplines. Based on these experiences, I decided to pursue graduate degree in Community Psychology to further examine these social justice issues related to education. From these personal and professional experiences, I developed my research interests in focusing on diversity and equality within science fields.

\section{Data Analysis}

Interview transcripts were analyzed using a modified grounded theory approach (Charmaz, 2006). The initial phase of coding was conducted to understand the data and to generate preliminary themes. During this initial phase, a research assistant and I read entire transcripts and selected text related to race and gender within the sciences. In the initial phase of coding, selections of text were closely examined and assigned codes, or brief descriptions of meaning (Charmaz, 2006). The codes in this initial phase described what was occurring within the data to develop a theory and lead to future focused analyses (Charmaz, 2006).

In the present study, microaggressions emerged as a theme during the initial phase of coding. Unlike quantitative methods, where a priori hypotheses are established and maintained throughout analysis, qualitative analysis, and specifically grounded theory, develops research questions that emerge from the data (Charmaz, 2006). My original research question was focused 
on barriers related to race and gender within the sciences. However, during the initial phase of coding, microaggressions emerged as a more relevant theme. The present research questions were established as a better fit to the data than the broader concept of explicit barriers.

In the second round of coding, or focused coding, the preliminary codes were applied through the analytic process (Charmaz, 2006). Focused coding was conducted using a qualitative software program, Dedoose (Dedoose Version 6.1.18, 2015). During focused coding, we applied the racial and gender microaggression taxonomies to the transcripts (Capodilupo et al., 2010; Sue et al., 2007). The research assistant and I read and coded each transcript individually and after each transcript we met to discuss any necessary revisions for the coded text. This discussion and revision of themes was guided by prior literature on racial and gender microaggressions (Sue et al., 2007; Capodilupo et al., 2010). Throughout the focused coding phase, better descriptions of the experiences emerged and revision to the coding framework was made to best fit the data (Charmaz, 2006). Furthermore, as we applied the microaggression taxonomies to the coding framework, several microaggressions were removed because they were not applicable to our data. For example, assumption of criminality is a common racial microaggression in which an individual assumes a person of color is committing a crime (Sue et al., 2007). Although we initially included this code in our focused coding because prior literature suggested it is a common racial microaggression, no instances occurred within the transcripts and it was removed from our coding framework.

After the second round of focused coding was complete and the coding framework of microaggressions in the sciences was finalized, a confirmatory round of coding was conducted. The confirmatory round of coding involved reading through coded text and confirming that codes were applied correctly. This ensured that changes made at later stages of the focused 
coding were applied consistently to all transcripts. After the themes were developed, comparisons were made between subgroups and identities of participants (e.g., student, graduate students, faculty, gender, and race/ethnicity).

\section{Establishing the Credibility of Findings}

Credibility within qualitative research is comparable to internal validity within quantitative studies (Lincoln \& Guba, 1986). Establishing credibility shows that developed themes are reflective of the experiences of participants within the study. Several techniques were implemented to achieve credibility of findings.

Member checking. Following the first round of coding in the larger study, all participants were invited to participate in member-checking feedback sessions. Each session was divided by role within the program (e.g. student, graduate student mentor, faculty advisor). Preliminary analyses were shared with all participants ahead of time and were reviewed with those who attended the feedback session. Of all participants invited, those in attendance included 3 students, 5 graduate students, and 6 faculty advisors at their respective sessions. Member checking was used to determine if the codes were reflective of participant experiences within the program and the sciences (Charmaz, 2006). Positive feedback from all participant groups suggested that our developed themes were reflective of experiences and that no major changes were needed in the clarification of themes. Individuals who were unable to attend the focus groups were invited to schedule individual meetings or submit feedback separately. Participation was incentivized by conducting raffles of $\$ 25$ gift cards to Target.

Memo writing. Throughout the data analytic process, memo writing was used to informally capture the analyst's thoughts about a transcript or selection of text (Charmaz, 2006). Memos allow for investigators to make connections across transcripts and to write down ideas 
for how to develop the themes further. In the current study, memos will be discussed between the pair of coders to aid in the refinement of the coding framework.

Analyst triangulation. Patton (1999) describes analyst triangulation as a method using multiple analysts to examine qualitative data to increase credibility of the findings. Multiple perspectives allow for the analysts to individually code the transcripts and to confer with the other coder to reduce individual biases that would emerge with only one investigator (Patton, 1999). In the current study, a research assistant and I examined the transcripts and continually meet to discuss codes. These meetings will be used to compare coded portions of the data, discuss memos, and refine the coding framework.

Peer debriefing. The process of peer debriefing will be used as an additional method to enhance credibility. Lincoln and Guba (1986) describe peer debriefing as the researcher working with a professional peer who is distant from the study. In this debriefing, the peer provides feedback to the researcher on a variety of components: biases, methods, definitions of codes, and developed themes (Lincoln \& Guba, 1986). For the current study, I debriefed with members of the research lab who are not a part of the study. Additionally, I consulted with a faculty member distant from the project review findings and conclusions.

Negative case analysis. To strengthen the findings further, negative case analysis was conducted. During this process, the data were examined for instances that contradict the developing evidence of the research questions. When a negative instance is found, explanations for the cases are provided and conclusions are modified to explain the case (Lincoln \& Guba, 1986). In the current study, negative case analysis was used throughout the focused round of coding. This included searching for instances in which microaggressions do not occur and providing explanations for such cases. 


\section{Results}

Analyses of the interview data revealed a variety of racial and gender microaggressions occurring in the sciences. In addition, the data indicate that microaggressions influence science education and career development. This section will describe the findings of Research Question One by describing the perceptions of microaggressions that emerged from the data. Following this description, findings from Research Question 2 on the influence of microaggressions on science career development will be described. Lastly, relevant patterns that emerged will be discussed throughout each section to illustrate findings from Research Question 3. Themes, subthemes, and patterns were included if they were described by more than three participants.

Given the small sample size and nature of responses, pseudonyms are used in place of participant names. Patterns of how microaggressions varied by participant groups (i.e. race, gender, educational stage) are discussed throughout the descriptions of findings.

\section{Perceptions of Microaggressions in Science Education and Careers}

Consistent with Sue et al.’s (2007) taxonomy of microaggressions, participants' experiences fit into four themes of racial and gender microaggressions in the sciences: (1) microinsults, (2) microinvalidations, (3) microassaults, and (4) environmental invalidations. A summary of themes is presented and their frequency of occurrence by participant career stage are presented in Table 3.

Although participants from different backgrounds endorsed each theme, patterns of endorsement occurred across race/ethnicity, gender, and age groups. For example, faculty who had been in the sciences for several decades recalled different types of microaggressions compared to STEMulate students who had less exposure within the sciences. In some instances, participants described their own experiences with a microaggression, whereas others described 
knowledge of another individual's experience. For instance, participants described learning from their colleagues or a family member's experiences of racial or gender microaggressions within the sciences. Even though the majority of themes describe personal or vicarious experiences, several themes include instances in which individuals endorsed a microaggression. This means that a participant perpetuated the belief that may negate or slight others based on their racial or gender identity.

\section{Table 3}

Themes of Microaggressions and Patterns by Participant Group

\begin{tabular}{|c|c|c|}
\hline Theme: & Description: & $\begin{array}{l}\text { Patterns by } \\
\text { Participant Group }\end{array}$ \\
\hline Gendered & Deliberate negative comments or behaviors & $50 \%$ Faculty; \\
\hline Microassaults & toward women in science. & $\begin{array}{l}\text { 30\% Graduate Student; } \\
\text { 18\% STEMulate } \\
(n=12)\end{array}$ \\
\hline Microinsults & $\begin{array}{l}\text { Demeaning comments or behaviors about } \\
\text { racial or gender identity in science. }\end{array}$ & $\begin{array}{l}\text { 77\% Faculty; } \\
58 \% \text { Graduate Student; } \\
\text { 55\% STEMulate } \\
(n=23)\end{array}$ \\
\hline Microinvalidations & $\begin{array}{l}\text { Comments or behaviors that negate lived } \\
\text { experiences of underrepresented scientists or } \\
\text { the role of race and gender in the sciences. }\end{array}$ & $\begin{array}{l}62 \% \text { Faculty; } \\
58 \% \text { Graduate Student; } \\
\text { 55\% STEMulate } \\
(n=21)\end{array}$ \\
\hline Environmental Invalidations & $\begin{array}{l}\text { Invalidations of race or gender that occur on } \\
\text { the system-level in science (e.g. laboratories, } \\
\text { departments, universities). }\end{array}$ & $\begin{array}{l}\text { 82\% STEMulate; } 62 \% \text { Faculty; } \\
67 \% \text { Graduate Student; } \\
(n=26)\end{array}$ \\
\hline \multicolumn{3}{|c|}{$\begin{array}{l}\text { Note }^{\mathrm{a}}=\text { Percent represents which proportion of participant group that described the theme; } n \text { represents total number of } \\
\text { participants who described that theme across groups. }\end{array}$} \\
\hline \multicolumn{3}{|c|}{ Another pattern was the anticipation of microaggressions. Specifically, STEMulate } \\
\hline \multicolumn{3}{|c|}{ participants described fears or beliefs that they will experience microaggressions related to their } \\
\hline \multicolumn{3}{|c|}{ race or gender in their future science careers. In comparison to instances of personal experience } \\
\hline \multicolumn{3}{|c|}{ with microaggressions or vicarious learning, the anticipation of microaggressions occurred when } \\
\hline \multicolumn{3}{|c|}{ participants described what they would expect to occur in the future. Examples of these instances } \\
\hline
\end{tabular}


Microinsults. The first form of microaggressions that participants reported were microinsults, which are comments or behaviors signaling rudeness or a degrading of one's race or gender (Sue et al., 2007; Capodilupo et al, 2010). Although microinsults can often be unintended by the perpetrator, they can send a demeaning message to the recipient's role in science. Participants reported two kinds of microinsults that occur within the sciences: (a) ascription of intelligence and (b) assumption of inferiority. Definitions of subthemes are presented in Table 4.

Table 4 Perceived Racial and Gender Microaggressions in the Sciences

\begin{tabular}{|c|c|c|}
\hline Subtheme: & Description $^{\mathrm{a}}$ : & Theme: \\
\hline Hiring Discrimination & $\begin{array}{l}\text { Occurs when a person is not interviewed or selected for } \\
\text { a position in science based on their gender. }\end{array}$ & $\begin{array}{c}\text { Gendered } \\
\text { Microassault }\end{array}$ \\
\hline Sexual Harassment & $\begin{array}{l}\text { Comments or behaviors of any unwanted sexual advance } \\
\text { or commentary. }\end{array}$ & $\begin{array}{l}\text { Gendered } \\
\text { Microassault }\end{array}$ \\
\hline Ascription of Intelligence & $\begin{array}{l}\text { Occurrences when an amount of aptitude in science is } \\
\text { assigned to an individual based on their racial identity. }\end{array}$ & Microinsult \\
\hline Assumption of Inferiority & $\begin{array}{l}\text { Occurrences that signal women are less capable than } \\
\text { men in science (e.g., physically, and academically). }\end{array}$ & Microinsult \\
\hline Invisibility & $\begin{array}{l}\text { Occurrences when women scientists feel overlooked, } \\
\text { powerless, or unseen by others because of their gender. }\end{array}$ & Microinvalidation \\
\hline Denial of Racism/Sexism & $\begin{array}{l}\text { Comments or behaviors that suggest racism and/or } \\
\text { sexism do not play a role in science. }\end{array}$ & Microinvalidation \\
\hline Restrictive Gender Roles & $\begin{array}{l}\text { Comments, behaviors, or structures that suggest that } \\
\text { women in the sciences should be following traditional } \\
\text { gender roles related to childcare, marriage, or } \\
\text { departmental housekeeping tasks. }\end{array}$ & Microinvalidation \\
\hline Lack of Women Scientists & $\begin{array}{l}\text { Environmental representation of women signals } \\
\text { messages about the acceptance and presence of women } \\
\text { in a science setting. }\end{array}$ & $\begin{array}{l}\text { Environmental } \\
\text { Invalidation }\end{array}$ \\
\hline Lack of Scientists of Color & $\begin{array}{l}\text { Environmental representations of people of color signal } \\
\text { messages about the acceptance and presence of people of } \\
\text { color in the science setting. }\end{array}$ & $\begin{array}{l}\text { Environmental } \\
\text { Invalidation }\end{array}$ \\
\hline $\begin{array}{l}\text { Absence of Science } \\
\text { Role Models }\end{array}$ & $\begin{array}{c}\text { Absences of individuals in science roles influences } \\
\text { aspiring scientist's ability to see themselves in a } \\
\text { particular setting. }\end{array}$ & $\begin{array}{l}\text { Environmental } \\
\text { Invalidation }\end{array}$ \\
\hline
\end{tabular}

a. Note. (Capodilupo et al., 2010; Sue et al., 2007) 
Patterns of Microinsults by Participant Group. The majority of participants $(n=23)$ described perceptions of microinsults occurring within the sciences. The largest proportion of microinsults were described by faculty in comparison to graduate and STEMulate students, the other groups also has high proportions. Specifically, over half of the graduate and STEMulate students discussed the theme of microinsults.

Ascription of intelligence. Ascriptions of intelligence occur when an amount of aptitude in science is assigned to an individual based on their racial identity (Sue et al., 2007). Ascriptions of intelligence occur specifically about one's racial identity, in which assignments of intelligence are ascribed to various racial groups. Although the recipient of this form of microinsult can perceive it as either positive or negative, the comment or behavior generalizes an individual's ability on the basis of their group membership by extending an assumption about the racial group. However, ascriptions of intelligence send a demeaning message about the recipient's own exhibited intelligence or aptitude in science.

When asked about the expectations others hold of him as a Latino male in science, Antonio, a high school STEMulate student described how individuals in science may assume a level of capability within science based on the lack of representation of Latina/os in science: "Well, especially with the small numbers that are in the science field of [Latina/os] . . it may seem that we're not capable of getting to that point." He described how individuals may ascribe a particular capability to Latina/os based on the representation of the racial group. This type of assumption would generalize ability based on the racial group, not necessarily a person's capacity.

In addition to perceptions of negative ascriptions of intelligence, some comments may be packaged as compliments. Jordan, an Asian male graduate student, described false ascriptions 
made about his math and science ability in relation to his racial identity. He described that "the positive side is people think I'm very good at math and science. So that works in my favor. Yeah, I'll take that. Even if I'm not good at math, so I'll say okay.” As Jordan described, ascriptions of intelligence can perpetuate false stereotypes about science ability based on one's racial identity despite being enveloped as a compliment.

Ascriptions of intelligence within science can also manifest as a shock or surprise when an individual from a racial minority group succeeds in a particular setting. In these instances, an individual's comment about the racial minority member's success is grounded in the assumption that the achievement is surprising. Shrishti, an Asian female graduate student, stated:

I think with people who are a minority in races or something. If they do something that a person from the majority does, their achievement is given a more-people are more surprised at their achievement rather than just accepting that, you know, even though they belong to a minority, they literally had the same kind of education as the majority.

As Shrishti observed, ascriptions of intelligence toward racial minority scientists sends the message that achievement or success among minority group members is abnormal. Further, the underlying assumption is that racial majority members do not warrant an additional acknowledgment apart from their own achievement. Her observation also explains that despite having equal educational attainment as scientists from racial majority backgrounds, the achievements of minority scientists are treated differently.

In sum, ascriptions of intelligence can send negative messages toward scientists of color that trivialize the individual's intelligence and attainment in science. Furthermore, while some of these comments may be intended to be positive, they convey the notion that success in the field is unusual compared to majority group members.

Assumption of inferiority. Similar to ascriptions of intelligence regarding racial identity, participants also described instances in science in which they faced assumptions of inferiority 
because of their gender (Capodilupo et al., 2010). This form of microinsult manifests itself through comments or behaviors made about a woman's science knowledge or job performance. These comments endorse a false stereotype that women are intellectually, emotionally, or physically inferior to men in science. Further, these comments are often not experienced by men in science, whose superiority and ability is frequently assumed. Dr. Schmidt, a white female faculty, described her experience facing assumptions of inferiority about her ability in the sciences:

... I've often run up with skepticism. People have even asked my male colleagues, "Does she really know how to use this? Does she really know what she's doing?" And I'm like, "Well, yes I came from one of the premier labs that use these techniques. I built this myself.

As Dr. Schmidt stated, individuals often think she is less capable in science despite her record of expertise. In addition, her male colleagues have asked about her own abilities, indicating that they assume to either know more than her or would be able to validate her science ability. Several participants shared this perception about false stereotypes about women's ability within science. This type of comment sends a message that female scientists are intellectually inferior within their fields compared to male colleagues.

In addition to female participants' personal experiences, male participants described vicarious experiences about gendered assumptions of inferiority occurring within science. In vicarious learning experiences, participants described instances in which they learned about other individuals experiences with microaggressions in the sciences. Dr. Sun, a white male faculty member, described his knowledge of a colleague's (a woman of color) experiences in science:

We had a long conversation at dinner about her career [in the sciences]. Her career, of not being taken seriously by her white, male usually supervisors. As a [scientist], she would order this treatment and those drugs and they would stop the orders and double check them because they just assumed that a Black [doctor], female, wouldn't be competent enough. 
Dr. Sun described his knowledge about his colleague's unique experience as a woman of color in the sciences. Her unique experiences within the sciences were attributed to both race and gender. Further, she experienced instances in which her competency in science was secondguessed. In particular, White male supervisors often perpetuated these negative assumptions of inferiority.

Evangelina, a Latina college student in the STEMulate program, described her fears related to others in the science field assuming she was not smart enough. In this description, she is describing an anticipation of a microaggression in the future. She stated:

I'm afraid, just because I'm a woman [who is] in a job where there's mainly males, I'm afraid that my opinion won't be taken as seriously, or I may be looked down upon. I think that may be a challenge later on, and I may have to stress how smart I can be in the field, and I'm actually there to help. I think that could be a big disadvantage.

Even though she is not in a science career yet, she is aware of how gender representation may influence how others perceive her science ability. She anticipates that individuals in science may look down upon her or perceive her as less smart because she is a woman.

Overall, microinsults targeted an individual's ability on the basis of their racial or gender identity. Given the intellectual nature of science, ascriptions of intelligence and assumptions of inferiority were commonly described by participants across all groups. These descriptions make clear that generalizations are made about an individual's race or gender that members from the majority group (White and/or male) do not experience. In addition to personally experiencing microinsults, some participants described their anticipation of microaggressions occurring in the future. As described in these instances, participants expect to experience generalizations about their racial or gender identity in the science setting.

Microinvalidations. Participants reported instances in which behaviors or comments were made that negated the role of race or gender in the sciences. These types of comments are 
influential because they diminish the experiences of individuals from marginalized backgrounds in the sciences. The three types of microinvalidations that emerged were: (a) invisibility, (b) denial of racism and sexism, and (c) restrictive gender roles.

Patterns of Microinvalidations by Participant Group. In contrast to other forms of microaggressions, participants from each career stage described microinvalidations at relatively the same proportion. Among the 21 participants this discussed this theme, the majority of faculty described this theme, whereas graduate and STEMulate students described it less often relative to other groups.

Invisibility. Several women participants described instances of invisibility (Sue \& Capodulipo, 2008), a microinvalidation that occurred for gender but not for racial identity in the present study. Participants described invisibility of women in science occurring when women felt powerless, unseen or left out on the basis of their gender by others in the science setting. As with other forms of microaggressions, it may be unintended by the perpetrator. Dr. Butler, a white female faculty, described experiencing invisibility within the sciences by saying, "you still have the old boy network [in science]. You can tell in certain conversations when men start talking around you or marginalizing." In her account, she described how in predominantly male science settings, female scientists are often left out of the conversation. As she described, this experience may be perpetuated by a network that sustains a space for men.

In another instance of invisibility, Lucia, a white female graduate student, described a much more explicit encounter of powerlessness as a result of her gender. She explained that she was the only woman in her science undergraduate course. After reporting an instance of gender harassment in her classroom, her gendered experience was disregarded compared to credibility of the male professor. She described: 
As the only female in the class, we had gotten back a paper. It was a group paper, which was the only group paper we ever wrote, but he had a paragraph with circles in red with a huge question mark over it. I go up to him and I say, 'Please, [Professor], I said, I understand you had a question with this. Can you please tell me why?' He goes, 'Guys, guys - 'because I was the only female in the class. This is what happened. Yes. He goes, 'Guys, this is what happens when women do science.' ...I went to the dean. The dean was like, 'Maybe you misunderstood.' I'm like, 'Nope. I didn't misunderstand. It was pretty point blank what he meant." He was like, 'He's a really good professor. He gets really good reviews.'

In this scenario, Lucia described two troubling experiences. First, as the only female in her class, her professor ridiculed her in front of the class on the basis of her gender. This assumption of inferiority, or microinsult, generalized her ability as a women scientist to be inferior to her male classmates. Second, after expressing the microinsult to the dean, her account was disregarded when calling attention to a gendered discrimination. Specifically, the microinvalidation of her experience was undermined by the dean in contrast to the credibility of the senior, male faculty. This example demonstrates a situation of powerlessness in which the participant's voice was not heard, which requires dismantling gender discrimination within the science academic setting.

Denial of racism and sexism. Another form of microinvalidation that participants described was the denial of racism and sexism. Participants often endorsed this microinvalidation, rather than perceiving them as a barrier that they have experienced in the sciences. While this type of microinvalidation is often unintended, it suggests that racism and sexism do not play a role in science. For example, Dr. Lee, an Asian male faculty, described, "I don't really see a barrier. It's just the - if the Hispanic people or the Black people wants to go into science, they have to study. They have to be told to study and do well at school kind of thing. If they do, then they'll make it." In his comment, Dr. Lee asserted that studying is more salient than race to succeed within science. Although this may have been unintended, the statement negates the reality of barriers that underrepresented groups may face in pursuit of science education. 
Similar perceptions were described related to gender in science. Jacob, a white male graduate student, described how he did not see sexism playing a role in his science lab:

Well, I don't think [sexism is] really a problem in today's society. I know it still exists, obviously, but I've had female undergrad and med students in the lab, and obviously STEMulate students, and they have been treated the same way, and they bring the same knowledge, and, if not, better knowledge half the time to whatever we're doing.

Even though harm from this microinvalidation may be unintended, the idea that sexism is not a problem negates the instances in which women in the sciences do experience sexism. Similarly, Diana, a white female graduate student, endorsed the idea that gender barriers do not exist: "I actually don't think there really are gender barriers for getting into the sciences. It's more just how hard and how long you study." As Diana stated, hard work and studying are more influential than gender barriers in science achievement. The endorsement of the denial of sexism negates that gender barriers may impact an individual's pursuit of success within science.

In many instances, participants described settings in which women were the majority as a basis to negate that sexism and gender inequality remains an issue. Javier, a male high school STEMulate student, said, “I don't think there's any [gender barriers] anymore, any barriers. I feel like they both have the same opportunities, male or female." In each of these instances, participants endorsed a microinvalidation suggesting that racial and gender barriers were not influential in pursuing science.

Restrictive gender roles. Many participants described the prevalence of restrictive gender roles that exist within the sciences. These microinvalidations are made by individuals within the field or structures that suggest that women in the sciences should be following traditional gender roles related to childcare, marriage, or departmental housekeeping tasks. The underlying assumption is that the restrictive gender role is not equally held for men in the sciences. Jordan, described how gender roles manifest within science laboratories: 
I guess females do have challenges [in science], which I can see if they're pregnant. People do see them as a negative thing. A [principal investigator] might take it as a negative thing because it takes away time from their lab which that is a problem for [principal investigator].... With females, I think they have a lot of problems, as well. As I just said, that they had to plan about so many different things. Since it's male dominated, they just won't understand what female problems are. ... A [principal investigator] might not be-I guess might not take a female student because he thinks that —or someone who is married because they think that she will get pregnant and that will take away time from her lab.

Jordan described how principal investigators, which are scientists that lead scientific projects, can impart restrictive gender roles on women. Specifically, investigators may perceive marriage and childbearing as detrimental to the progress of the research project or laboratory. As Jordan pointed out, the degree to which males outweigh females in the sciences contributes to this misconception, which ultimately negatively impacts female scientists who want to work in the sciences. Furthermore, Jordan's description acknowledges how women may be intentionally discriminated against in hiring on the basis of restrictive gender roles (see Hiring Discrimination below).

Similarly, Dr. Carter a white female faculty elaborated on restrictive gender roles toward women scientists by describing how those roles are embedded in the grant funding process. She stated:

Maybe a woman might be expected to take care of the kids and get a little bit of leeway and things, but a man cannot do that, and so there is a pressure for the men not to necessarily help out as much also. Even with the NIH, we apply for grants, and they'll give an extension to your new investigator status if you're a woman for maternity leave, but they won't do it for men.

Although maternity leave for women is helpful, the absence of paternity leave for men sends a message that men in science are not expected to care for their children. In addition to this instance being a restrictive gender role for women scientists, it is also occurring at the systemlevel as a policy decision. This is an example an environmental invalidation that will be further discussed in the next section. 
In another instance, restrictive gender roles acted as a barrier toward women graduate students from pursuing higher education in science. Lucia, describes,

I was told many, many, many times in my undergraduate that no one would write me a letter of recommendation for graduate school cuz I'd end up just getting married and staying at home and not actually using my degree, and therefore, a lot of them wouldn't write for me. A lot of [faculty] said, "Many women fail out and take a master's.

As Lucia illustrates, she frequently heard restrictive beliefs about her role in science and perceived roles of marriage and homemaking. The restrictive gendered role assumptions held by faculty created a barrier for Lucia in pursuit of a graduate degree in science.

While faculty and graduate students described experiences within the sciences, STEMulate participants described how more restrictive gender roles impacted their role in science education more broadly. When asked about the expectations of a Latina committed to pursuing science, Yesenia, a Latina college student in the STEMulate program, stated:

I feel like [family] expect you not to be something in life. They, in a way, make you, based on society in and around, that girls are not meant to be as high as a man is, or be as knowledgeable as them. Like man is more dominant and they look down on you just because you're a girl. That kinda' makes you think twice about everything that you're doing or educational-wise too.

Because everybody around you just tells you, "Okay, well, why are you gonna be in school?" Or, "Why are you gonna go further in life? You're a girl. You're not meant to be in that. You're just meant to be at the house cleaning, taking care of kids, whatever.

Yesenia explained that expectations from others often include childcare and homemaking, rather than pursuing education. These expectations of her as a young, Latina woman are not applied to men, who may be expected to pursue school.

Gendered microassaults. Another overarching theme within the data were gendered microassaults. A microassault is characterized based on its intention and deliberateness toward someone based on their gender (Sue et al., 2007). Although microassaults occurred less often than other forms of gendered microaggressions, they were a theme within the data. Furthermore, participants did not report racial microassaults within the sciences. Participants reported two 
types of gendered microassaults occurring within the sciences: (1) gendered hiring

discrimination and (2) sexual harassment.

Patterns of Gendered Microassaults by Participant Group. Although gendered

microassaults were described by fewer participants $(n=12)$, patterns emerged between the career development stages. Specifically, gendered microassaults were most often described by faculty and graduate students, whereas few STEMulate students reported experiencing gendered microassaults within the sciences. Furthermore, while women scientists often described the personally experiencing this theme, men within the sample utilized vicarious experiences to describe the existence of gendered microassaults in science settings.

Gendered hiring discrimination. A form of gendered microassault that emerged in the interview transcripts was hiring discrimination based on gender. Hiring discrimination occurs when a person is not interviewed or selected for a position based on their gender. In the following examples, participants described their own or others' experiences related to hiring discrimination within the sciences. In many instances, faculty reflected on earlier times in their careers where discrimination practices may have been more common and not addressed as a legal issue by their institution. Dr. Greene, a white male faculty member, described his wife's experience of hiring discrimination in the sciences by saying:

My wife was gonna be doing [science] and went to a job interview and her name was [a unisex name]. There are men who spell their name that way. She showed up for a job interview and the man who was supposed to interview looked at her and said, "You're a woman. I can't interview you for this job. You can’t do this job.

Dr. Greene's knowledge about hiring discrimination arose from his wife's personal experience. While this experience occurred at an earlier point in his career, the situation illuminates the presence of intentional practices that prevented women scientists from working in science disciplines. 
Although Dr. Greene's example is a vicarious learning experience of hiring discrimination within science employment, others described the less-monitored process of selecting individuals to work in their lab. In these instances, faculty were selecting between students who may have been previously admitted into the program. The placement of students within labs is a less formalized process within the sciences and may allow for more gender discrimination to occur. Sam, an Asian female graduate student, described her perception of gender discrimination in lab placement:

I've heard horror stories about just faculty won't take a girl—a female graduate student just because they don't wanna deal with - they have this kind of ingrained in their head that girls can't do science or math. There's a lot of these old-school thinkers who still don't really accept a woman in science. They don't think it's-they don't think that women can do the job.

As Sam described, faculty may make lab placement decisions based on gender. Her description also illuminates another example of how assumptions of inferiority, or beliefs that women are less capable at science then men, may negatively influence women in the sciences. Participants described the way that hiring discrimination manifests itself in the lab placement process within science academic settings. In these instances, the biases of faculty toward women may influence them not to select someone in their lab.

Sexual harassment. Despite laws and institutional policies prohibiting sexual harassment in the workplace, participants described instances of such microassaults occurring in sciences. Sexual harassment is considered any unwanted sexual advance or commentary. Dr. Weber, a white male faculty member, described a vicarious learning experience by describing a female family member's experience within the sciences by saying:

[One of my family members] wanted to go into [science]. She was in a graduate program and doing really well, but she was working in somebody's lab. She was getting hit on by another scientist and it was-it's a full professor. 
Dr. Weber described how his sister's experience of sexual harassment within the sciences.

Specifically, the family member was receiving unwanted sexual attention within the laboratory setting. Furthermore, Dr. Weber's family member was a graduate student while the perpetrator was a full professor, creating an unequal power dynamic within the setting

In some instances, female faculty described experiences from when they first entered science. While these experiences occurred at an earlier point in their career, they signal prior experiences of a specific generation of female scientists. Dr. Schmidt, described:

It was more when I was a graduate student so it was both as being subordinate and as a woman. I explicitly remember that my department chair - as a graduate student, we were taking the elevator up and they had those mirrors in the front of the elevator so you can see behind you, and he was blatantly just staring at my ass. I just kinda turned around and looked at him like, "I see you." It was just like a, "Come on, you're kidding me, really? Really, in the elevator? I can see you." ... I think it's an impediment at a couple levels. The elevator incidents to me are eye-rolling, but it speaks to a bigger issue of, "You think you can invade my personal space like that? Do you not respect me? If I were a faculty member, would you be doing that? If there were other people in the elevator, would you be doing that?" It was just sort of a reminder that I was subordinate and was it because I was a woman or was it because I was a graduate student?

As Dr. Schmidt explained, while the incident may have seemed minor, it nevertheless illuminates a larger issue. The male faculty member's actions within a position of power suggested he did not respect her. Further, she described experiences of fellow graduate students while she was in school who were expected to share rooms with male faculty at conferences. These explicit advances toward women in science settings create a negative climate.

Although some instances of hiring discrimination and sexual harassment occurred earlier in faculty career development, there were instances in which these microassaults occurred more recently. These examples provide a counter-narrative to the misconception that policies and laws have eradicated the negative occurrences of sexual harassment and gender discrimination.

Environmental invalidations. Several microaggressions pertaining to race and gender occurred on an environmental level. Participants described three types of environmental 
invalidations occurring in the sciences, or occurrences and messages that occur on a systemic basis. These microaggressions signal messages toward a scientist's race or gender that the science setting (e.g., laboratory, department, and field) may not be for them or members of their identity group. These types are the: (1) lack of women scientists, (2) lack of scientists of color, and (3) absence of role models in science.

Patterns of Environmental Invalidation by Participant Group. In contrast to previously described findings, STEMulate students described perceptions of environmental invalidations more often than microinsults, microinvalidations, or microassaults. Specifically, $82 \%$ of STEMulate students described environmental invalidations occurring in the sciences related to race or gender. Additionally, the majority of faculty and graduate students described this theme, making it a prevalent theme within the data.

Lack of women scientists. Participants across all backgrounds and education levels acknowledged that women are underrepresented in the sciences. Many participants described how the underrepresentation of women signaled negative messages about the acceptance and presence of women in a science setting. Settings ranged from the visible gender makeup of employed faculty, laboratories, classrooms, and scientific disciplines more broadly.

Jacobdescribed the lack of gender representation in his department by stating:

There are no, really, there are no Ph.D.'s that are female in [this department]. There's one grad student that's a female, and then my lab manager is a female, but that's it, which is crazy. I feel like we're down the hall from [another department], and they've got tons of female professors, Ph.D.'s.

As Jacob described, gender representation varies across settings within the sciences. At his university, he noticed how women may have a presence in some departments and roles but are absent in others. 
Lucia, described her experience with lack of gender representation throughout her science education by saying:

Being a female, I feel, is a little bit of a detriment. . . . My entire undergraduate career was very challenging. I was the only female in either one of my undergraduate degrees and the only female in research. I heard every comment, every opinion from every male professor I had. Luckily, it's less difficult at [at this university], but I feel like being a female is definitely still really challenging.

Lucia points to different settings throughout her science education where she experienced a lack of gender representation. As an undergraduate student and in research laboratories, she was the only female scientist. Although her current science setting has greater gender representation, she described that gender representation contributed to challenging experiences.

Dr. Schmidt, described how this environmental invalidation shaped her decision-making related to faculty positions:

[Gender representation] certainly shaped where I went for faculty positions. Like I said, some of the departments had very few women, which — normally, wouldn't necessarily bother me so much, depending upon the attitudes of the men in the department. It was clear even just from how they prioritized their offices and their pictures and their families. They had a little picture of their wife or kids but their big science achievements were all over the room. Whereas, for example, here there's - we're lucky to have a lot of women in my department but regardless, even the men and the male faculty members across all departments, very clearly, equally put their families and careers on equal status or at least we're given enormous amounts of respect. It was evident even from just how they organize their offices and how they approach you that this was - it wasn't that women and spouses were subordinate and my career's above everything.

In this instance, Dr. Schmidt described how gender representation was visible in her pursuit of faculty positions. Furthermore, within male-dominated departments the environmental cues related to family and career signaled different messages about how women would be viewed among male colleagues. In some instances, male scientists prioritized career achievements in their offices, whereas other offices had clear representations of valuing women in both family and career.

The descriptions provide evidence that within science settings, the lack of women scientists was visible across various settings, such as departments or universities. Additionally, 
the underrepresentation of women may influence how they perceive their own role within the science setting.

Lack of scientists of color. Similar to descriptions of gender representation, participants described perceptions related to the lack of representation of people of color in the sciences. For example, Joshua, a Latino high school student in the STEMulate program, described how being Latino has influenced his experience pursuing science education by saying: "Being [Latino], that just, like, sets you back even more. There's a lot of Caucasians in the [science] fields, and less of the other ethnicities." As Joshua described, he has perceived science fields to be predominately White, in which the representation of people of color has been lacking. Furthermore, he described this as a barrier toward the pursuit of science education.

In a similar instance, Javier, described how a lack of representation of people of color exists within science settings. When asked about the barriers that Latina/os may experience and his experience as Latino male pursuing science education, he stated:

Well, I feel like there's not enough of us, of male [Latinos] in the field, or [Latina/os] period, in the science field. . . . Since there's not enough of us, I feel like they feel like, "Oh, you guys don't know this topic as well as we do since there's more of us, more Caucasians.

As Javier described, he perceived there to be few Latino men specifically, and Latina/os generally, in the sciences. Javier also discussed how the presence of more White individuals than Latina/os in the sciences may influence perceptions about Latina/o scientists. Specifically, he perceived a barrier in which his racial group may be perceived as less knowledgeable as a result of the lack of representation of Latina/os.

Absence of science role models. Many participants described the lack of science role models as a potential barrier that racial/ethnic minority's face in the sciences. In contrast to the previous subthemes, lack of women scientists and lack of scientists of color, the absence of science role models addressed the broader exposure to scientists. Namely, this environmental 
invalidation explains how the absence of viewing individuals in science roles influences aspiring scientists' ability to see themselves in a particular setting. Lucia, , described this subtheme by explaining how it is difficult for program participants to aspire to be a scientist if they do not personally know anyone in that position. She described the influence of science role models in underrepresented communities by saying:

It's because in [the Latino] community, the highest form of education in the medical field, given their surroundings [was a nurse]. They saw nursing as the pinnacle, the apex of being a medical professional. They don't have surgeons next door. They don't have ER doctors. They don't have OB/GYNs. They don't have radiologists. It's very uncommon for the population that we serve to have higher education, and when they do, they really have a four-year degree. The best four-year degree that has the most stability in the field is nursing. These young women would come in and say, "I want to be a nurse," 'cuz the only thing they've seen modeled. Then when we talk to them about, "Nursing's fine. What about being a doctor? What about being a radiologist? What about being a biostatistician? What about being a Ph.D. researcher? What about being a dentist?" They're all like, "Oh, really?" Because they don't see it modeled in their community, they do not ever think about that as being an option for them. They see it as outside of their reach. We're glad when they say they want to be a nurse because it means they want to at least get a four-year degree, and it means they want to help people in the community in the medical profession.

As Lucia described, science role models play an important example in identifying potential career options. While students may view nursing as a common profession, they are seldom exposed to other scientists, such as radiologists, biostatisticians, and $\mathrm{PhD}$ researchers. This absence of science role models on the systemic level within communities influences student perceptions of their own role with the science field.

Evangelina, was asked about what she looks forward to when pursuing a career in sciences. She described the absence of science role models within the Latino community by saying:

Being able to say that I am [scientist] would be great. Also, I think, a lot of times, in [my community], where I grew up, there's not a lot of female role models. I would really like to go into the high school and say, "Oh, look what everyone else can do. Here are the steps you can take," which is basically what the [STEMulate] program does with us, and tries to get more women into science as well. 
Evangelina described that in her community, she did not have many female role models.

However, she looks forward to pursuing science in order to be a role model for students in her community.

In sum, the absence of science role models can influence whether underrepresented students can picture themselves within the science fields. This subtheme represents environmental invalidations that occur on the systemic level.

\section{The Role of Microaggressions in Science Education and Careers}

Participants described the previous microaggressions as potential barriers for women and racial/ethnic minorities within the sciences. Participants reported several ways that microaggressions played a role on their education and career development in science, which fell into five overarching themes: (1) detrimental to psychological well-being, (2) mobility across science contexts, (3) pressure to prove ability and competence, and (4) sense of social isolation. A summary of themes is presented in Table 5.

Table 5 Role of Microaggressions on Science Education and Careers

Theme: Definition:
Detrimental to Psychological Microaggressions influence recipient psychologically, such as confidence or the Well-being intellectual tax of interpreting the microaggressions.
Mobility Across Science Influenced not only if the person stayed in a science job or program, but if they Contexts stayed in science altogether.

Pressure to Prove Ability and The need to reaffirm your intellectual ability and aptitude for science in the Competence presence of racial and gender microaggressions.

Sense of Social Isolation

The lack of similar individuals from your identity (gender, race/ethnicity) created situations without individuals to relate to, feeling alone, lack of community.

Detrimental to psychological well-being. One of the implications of microaggressions more broadly is their detriment to the psychological well-being of the recipient (Sue, 2010). This can often manifest as having to decipher the meaning of, or what was intended by, the 
perpetrator. Participants described specific situations in which microaggressions in the sciences impacted their psychological well-being, such as negatively influencing their confidence, the intellectual tax of deciphering the microaggressions, and their mentality generally. Dr. Schmidt, described the impact of an experience of sexual harassment from a male faculty member. After explaining the microassault, she described the detriment to her psychological well-being this experience caused as follows:

I think [microaggressions are] an impediment at a couple levels. The elevator incidents to me are eye-rolling, but it speaks to a bigger issue of, "You think you can invade my personal space like that? Do you not respect me? If I were a faculty member, would you be doing that? If there were other people in the elevator, would you be doing that?" It was just sort of a reminder that I was subordinate and was it because I was a woman or was it because I was a graduate student? It was that sort of - am I going to be fighting this my whole life? Again it just weighs in the back of your mind, you just kind of keep trudging forward but if it just continues to accumulate, it becomes this increasing very amorphous psychological weights you just carry around.

In this instance, Dr. Schmidt described the many ways she could decipher the incident and sparked her worries about whether this type of negative occurrence would continue throughout her career. Furthermore, she describes the psychological toll created by the microassault she experienced. The burden of asking oneself these questions is detrimental to the psychological well-being brought on by the microassault, not uncommon for those who experience microaggressions in varying contexts (Sue, 2010).

Participants also described the impact of the lack of women scientists on their psychological well-being. Dr. Carter, described her experience:

One thing that just really bothers me is just the-I always call it the 20 percent rule, which is if you look around, whether it's editorial boards or departments or talks at meetings or even seminar series here, you rarely get above 20 percent in terms of representation by women. ... That's also something that - how that impacts our mentality and what we're thinking about in terms of our confidence.

As Dr. Carter described, a lack of women as speakers in seminar series' or serving on editorial boards influences female scientists' mentality. Specifically, Dr. Carter described that a lack of gender representation, or environmental invalidation, influences women scientists' confidence. 
Mobility across science contexts. Participants described instances when

microaggressions influenced their mobility across science within the contexts of education and careers. Specifically, participants reported how microaggressions influenced whether they stayed in a role or program. In some cases, participants described vicarious knowledge of other scientists who left science altogether. Dr. Weber, described the impact of sexual harassment in science academic settings and how it negative influenced a family member's pursuit of science. He explained:

[One of my family members] wanted to go into [science]. She was in graduate program and doing really well, but she was working in somebody's lab. She was getting hit on by another scientist and it was - It's a full professor. It just really, I don't want to say devastated, but it really hurt her, and then she ended up leaving grad school because of that and other types of situations like that. I mean there was no question that she was smart enough and hard-working enough, but she was treated differently, and in a way that made her uncomfortable, and then decided that it's not worth it for her. That's, well, it's a shame. It's a loss for the science community.

As Dr. Weber described, sexual harassment, or unwanted sexual attention, from a male superior influenced his family member's pursuit of a science career. Despite his family member having demonstrated merit and competence within science, the negative experiences of gendered microassaults contributed to her choice to leave science altogether.

When asked about experiences of discrimination or harassment, Dr. Chase, described how restrictive gender roles in the sciences contributed to her choices regarding work environments as a graduate student by stating:

When I was a graduate student looking around for labs, this one [scientist] said to me, "You wouldn't be cut out to this job ...The work requires you just stay and sometimes you have to stay past 6:00 and a lot of times women have to go and take care of the family." I listened to that and like, "Yeah...I'm not working here."

In this instance, Dr. Chase described how comments reflecting restrictive gender roles surrounding childcare practices within the science workplace influenced her decision to work elsewhere. 
Overall, participants described how microaggressions influenced their mobility across science contexts. In some instances, individuals strategically moved toward contexts absent of the microaggression, such as avoiding departments with restrictive gender roles, whereas other recipients of microaggressions moved out of science altogether.

Pressure to prove ability and competence. Participants described how microaggressions created pressure to prove their ability and competence in science. Specifically, this pressure manifested as the need to reaffirm their intellectual ability and aptitude for science, or the veracity of their accomplishment in science. Furthermore, participants described having to dispel harmful beliefs that they were only provided the position based on their identity. John, a Latino male graduate student, described experiencing this specific form of pressure as Latino scientist by stating:

Because you will get a certain amount of that you have to - in any minority, you have to do better so people respect what you do and look past what they see. I think that there can be a higher pressure on that, and the fact that I think, to a certain extent, it's that they feel like they may have to prove themselves if there is - if they think that their colleagues think that they got in through a backdoor because of their ethnicity.

As John described, this pressure derives from ascription of intelligence made about a scientist of color that suggests an individual from a minority background achieved their position because of their ethnicity, rather than their own abilities. In the face of these microaggressions, individuals from minority backgrounds may feel pressure to dispel these negative assumptions in science contexts. This particular microinsult may disproportionately contribute to scientists of color seeking to prove themselves, which scientists from majority racial groups may not have to consider.

Women participants also described this pressure in relation to their gender in the sciences. Evangelina, described how assumptions of inferiority, or negative comments about her ability as a woman scientist, may influence her career in science. She stated: 
Playing off of that being-the-minority thing, I'm afraid, just because I'm a woman, some- - being in a job where there's mainly males, I'm afraid that my opinion won't be taken as seriously, or I maybe looked down upon. I think that may be a challenge later on, and I may have to stress how smart I can be in the field, and I'm actually there to help. I think that could be a big disadvantage.

Evangelina is worried that in male-dominated science settings, she may have to prove herself to others on several career components. She explained that in a male-dominated setting, she may have to assert to her opinion, and prove her science competence and contributions in the science field. This is an added burden that underrepresented individuals may have to shoulder that men in science settings may not.

In sum, the presence of microaggressions, such as assumptions of inferiority or ascriptions of intelligence, were related to participants' descriptions of feeling pressure to prove their ability and competence in science settings.

Sense of social isolation. Participants described how microaggressions created a sense of social isolation, or feeling as though they did not have a relatable network within the sciences. Social isolation can be described as a lack of network of individuals who shared one's identity (gender, race/ethnicity). In these instances, participants described being without individuals to relate to, feeling alone, and having a lack of community. Social isolation was most often described in relation to the underrepresentation of women and racial/ethnic minorities in the sciences. For example, when asked about the barriers he may face in in pursuing a science, Javier described:

I think that since ... there's not enough [Latina/os] and not a lot of support system, like, "Oh yeah, we've probably been through the same thing and we got through it. It's just very challenging." There's not enough support system, I would say, since [Latina/os] —in school there's not enough Latinos you could compare yourself or are almost alike.

The lack of representation of Latina/os in science, an environmental invalidation, may influence an individual's perceived support network. In the absence of a support network, there may not be an individual to validate challenges one might experience in the science setting. Furthermore, the 
lack of network prevents the ability to compare your own science experiences with individuals from a similar background.

Evangelina also described how a lack of representation of Latinas in science influenced

her experiences in science education, she described:

Really, I think it has more dampened being in the science, just because, in our community, we don't see a lot of [Latinas] in the science field. A lot of times, we just see parents, they want their children to stay at home, or they immediately just start a family and not even go to college. With the [school] I'm at now, I see a lot of Caucasians, and it really makes me feel isolated, but it also gives me this determination to basically help the statistics and be different from what others tend to do.

A lack of representation of Latina/os at Evangelina's school makes her feel isolated in the sciences. Conversely, she also described being determined to overcome the occurrence to challenge the existing representation in the sciences.

Participants also described gendered experiences of social isolation in the sciences. Dr.

Butler, reflected on her experiences in science by saying:

I have absolutely seen the male dominance in [science]. I have shattered many a glass ceiling. It's been a fight. I think it's much better for women now, but it was absolutely a fight, a struggle.

Nothing, no networks were made for me. I had to create them all myself. There was nothing that was given to you by virtue of the position.

Dr. Butler is describing that in a male-dominated setting where women are underrepresented, she had to develop her own networks. As she described, the networks did not come with the position. Rather, she had to create them for herself. The lack of relatable networks that Dr. Butler described is a burden that underrepresented individuals in the sciences must navigate in comparison to their represented colleagues.

Participants described how microaggressions related to experiences of social isolation. Social isolation was most commonly related to environmental invalidations, such as a lack of representation among women or scholars of color in the sciences.

\section{Discussion}


The goal of the present study was to examine perceptions of racial and gender microaggressions in the sciences from the perspectives of high school students, college students, graduate students and faculty. Guided by Social Cognitive Career Theory (SCCT; Lent et al., 1994) and the microaggression taxonomy (Sue et al., 2007; Sue \& Capodilupo, 2008), the current study explored how racial and gender microaggressions in the sciences play a role in science education and career development. The findings of the current study provide evidence that racial and gender microaggressions occur within the sciences and play a negative role in science education and career development, as described by participants of various backgrounds and educational stages. Notably, the findings of this study indicate the influential role of environmental invalidations on one's experiences across the science pipeline and the role microaggressions play in underrepresented individuals' mobility across science contexts.

The current study makes three key contributions to the existing literature on microaggressions. First, this study included perspectives across developmental stages within the science pipeline. This is an important contribution as most existing literature focuses primarily on graduate student perspectives with only one study from the perspective of high school students (Grossman \& Proche, 2013). Second, the findings add support to a dearth of empirical investigations on gender microaggressions and environmental invalidations. This contribution is especially important when understanding the experiences of underrepresented groups in the sciences wherein gender and environmental invalidations may play an important role. Lastly, the findings of this study support SCCT and the role of distal factors on the science career development process. Specifically, surrounding factors of race and gender that are perceived by individuals within the contextual environment have a negative influence on their pursuit of science education and careers. 


\section{Perceptions of Racial and Gender Microaggressions in the Sciences}

The findings of the present study provide additional, yet nuanced, support to the existing microaggression literature. Several themes of racial and gender microaggressions discussed within the present study reflected existing microaggression taxonomies (Sue et al., 2007; Sue \& Capodilupo, 2008). For example, participants in the current study frequently described ascriptions of intelligence about racial identity. Furthermore, they were described with both positive and negative intentions. The findings support an investigation by McGee, Thakore, and LaBlance (2016), which indicated that Asian college students in STEM experience the "model minority" stereotype, an ascription of intelligence microaggression often made with positive intentions yet perpetuates negative racial generalizations of scientists of color in the sciences.

Findings of gender microaggressions within the present study relate to the broader gender microaggression taxonomy (Capodilupo et al., 2010; Sue \& Capodilupo, 2008) as well as prior investigations of women's experiences in the sciences. The themes of invisibility, restrictive gender roles, and assumptions of inferiority in the current study support the prior work of Barthelemy et al. (2016), wherein women graduate students described experiencing these forms of gender microaggressions in physics and astronomy. While Barthelemy et al. (2016) provided evidence of gendered microinsults and microinvalidations, the current study provided additional evidence for gendered microassaults and environmental invalidations related to gender (e.g., lack of women scientists). This is an important contribution given the limited empirical investigations on gendered microaggressions broadly, and within the sciences specifically.

The findings of environmental invalidations within the current study support prior research on the role of the environment as a vehicle for perpetuating racial and gender microaggressions. Specifically, the subthemes of lack of scientists of color and absence of role 
models were perceived to be barriers to pursuing science education and careers. These findings support the original taxonomy of racial microaggressions (Sue et al., 2007) by illustrating that a lack of individuals from one's racial group at a science institution can signal macro-level messages about who is welcome within that settings. Furthermore, the finding of lack of women scientists provides support to prior research about gendered, environmental invalidations (e.g., Lester et al., 2016). The physical arrangement of the science classroom can be exclusionary toward women who want to pursue science (Lester et al. 2016). The findings of the current study expand on the understanding of gendered, environmental invalidations. Specifically, we found that lack of women scientists and scientists of color across departments, labs, and universities served as a barrier to pursuing science education and careers.

In sum, the findings support prior research and provide an important contribution to the literature. Namely, the current study added empirical evidence of gendered microaggressions and environmental invalidations.

\section{Role of Microaggressions in Science Education and Career Development}

The findings of the current study illustrate the negative role of microaggressions as themes that emerged organically from the data. Furthermore, the described themes have important contributions for future research on SCCT and interventions along the science pipeline. The theme pressure to prove ability and confidence in the study supports the work of Trevino et al. (2010), wherein the authors described microaggressions faced by scholars of color along the academic pipeline. Although prior investigations have described this in relation to racial microaggressions, we found additional support that it occurs in relation to gender. This is an important contribution to the microaggression literature because women and scientists of color may undergo added pressure within science that their colleagues from represented groups 
may not face. Consistent with prior research (Nadal et al., 2014) this pressure may be added for individuals with multiple underrepresented identities, such as women scientists of color.

The finding of mobility across science contexts provides a unique contribution to understanding the negative role of microaggressions in science education and careers. Our findings revealed that microaggressions may influence how individuals from underrepresented groups navigate science contexts. In some instances within the current study, this included moving to a different science department or discipline, or attrition from science altogether. This is an important factor to consider in efforts to increase representation of women and scientists of color in STEM. Specifically, microaggressions may contribute to attrition from a science setting or discipline, irrespective of one's interest and ability in science.

Another important contribution is a demonstration of the important role of environmental invalidations in the negative influence of microaggressions in science education. Specifically, themes of mobility across science contexts, detrimental to psychological well-being, and sense of social isolation were often described by participants in relation to environmental invalidations. Prior research has exhibited the negative role of environmental microaggressions in the feelings of belonging among of scientists of color (Brown et al., 2016) and women scientists (Lester et al., 2016). However, in the current study we found that environmental invalidations were also related to themes of detrimental to psychological well-being and mobility across science contexts. These findings provide evidence of the nuanced influence of environmental invalidations in the sciences. This evidence is especially important because environmental invalidations may play an important role in detracting underrepresented individuals in science contexts by signaling to them which settings they feel the most belonging. This adds to the 
existing evidence that specifically describes the negative role environmental invalidations can have on the experiences of underrepresented groups in the sciences.

\section{Patterns of Microaggressions by Participant Identity}

While many of the themes that emerged in the present study support prior examinations, the patterns of perceptions of these microaggressions among participants add a unique understanding to microaggression research. Several patterns emerged across participant identities, such as race, gender, or science career development stage. Consistent with prior research (Nadal et al., 2014; Grossman \& Proche, 2013), women participants reported more perceptions of microaggressions than men in the sample. This was especially true for gendered microaggressions of assumptions of inferiority. Similar patterns emerged for racial microaggressions. For example, participants of color described perceptions related to ascriptions of intelligence than White participants.

We found patterns of difference between science career development stages, similar to that of Brown et al. (2016) in which graduate students reported fewer perceptions of microaggressions than faculty. One important contribution of the present study is that STEMulate students reported fewer perceptions of microassaults, microinsults, and microinvalidations compared to graduate students and faculty. However, they reported more instances of environmental invalidations. This is a unique finding that may be representative of the sample or their developmental stage. For example, faculty have had more time and exposure to experience microaggressions compared to STEMulate students who have primarily experienced science within their high schools and STEMulate program. Additionally, there were differences between perceptions of microaggressions between high school and college STEMulate students. Specifically, participants who had moved from a homogenous high school 
setting toward predominately White universities had experienced more microaggressions than their high school counterparts. Moreover, as aspiring scientist's progress from high school settings toward academia, science settings become less diverse and predominately represented by White men.

Descriptions of environmental invalidations and anticipation of microaggressions from STEMulate students has implications for understanding retention and well-being in the science pipeline more broadly. Specifically, if high-performing science students are perceiving systemlevel invalidations about their identity early in their career, this could be a risk factor for potential attrition from the sciences as described by prior research (Fouad \& Santana, 2016). Furthermore, the unique pattern of anticipation of microaggressions requires further investigation. Namely, how do students develop these anticipations and do some students choose to leave the science pipeline for fear of interpersonal microaggressions related to racial and gender identities? Interventions to develop understanding among scientists or to address these negative messages students receive about their racial and gender identity are needed to maintain underrepresented groups in science fields.

Another important contribution of this study was the pattern of vicarious learning. In instances where an individual may not have personally experienced microaggressions, many reported a vicarious learning experience. For example, if a male participant had not personally experienced microaggressions, they would often refer to a woman colleague or family member who had experienced microaggressions. The unexpected pattern of vicarious learning of microaggressions within the data suggests that individuals who do not experience microaggressions are also recognizing their existence and influence their presence have on individuals within the sciences. This pattern may be particularly important given a recent critique 
of microaggression theory that takes issue with the subjective nature of perceptions of microaggressions (Lilienfeld, 2017). Although validation from others should not be the aim of research on microaggressions as the instances are experiential in nature (Sue, 2017), the pattern of vicarious learning in this study adds to the understanding of how microaggressions are recognized by individuals other than the recipient. This finding of vicarious learning may have potential future implications for preventing microaggressions.

In sum, the patterns of findings in the current study provide a unique contribution to the microaggression literature given the dearth of examinations among high school aged students. Furthermore, the pattern of vicarious learning illustrates potential future research that aims to prevent microaggressions within science settings.

\section{Implications for Social Cognitive Career Theory}

The present study contributes to the literature by examining microaggressions through the lens of SCCT. While no investigations have explored microaggressions in the sciences through this lens, the findings of this study indicate how SCCT may provide understanding about increasing the retention and well-being of scientists along the science pipeline.

The pattern of anticipation of microaggressions relates to the STEMulate students' expectations of future experiences in science fields related to their race and gender identity. This theme appears to relate to the outcome expectations as described in SCCT, or outcomes an individual's believe will occur in relation to a career or educational behavior (Lent et al., 1994). Similar to existing research on racism and sexism as contextual factors in SCCT (Chaves et al., 2004; Fouad and Santana, 2016), anticipation of microaggressions may influence future goals and actions of an aspiring student in relation to science. This is a unique finding as students who 
may anticipate microaggressions in a science discipline, department, or university and choose to leave science or move toward a different science setting.

Another implication for SCCT is the finding of mobility across science contexts. This finding suggests that microaggressions may influence whether a scientist from an underrepresented background choose to remain in their field or move to a new science setting. As described by Fouad and Santana (2016), presence of contextual factors, namely racial or gender microaggressions, may influence actions related to science career development. This finding is important for future investigations of SCCT that seek to explore increasing retention and well-being of underrepresented groups in the STEM fields. Furthermore, interventions that seek to address disparities STEM pipeline should consider the role of microaggressions on key STEM-related choice behaviors.

In sum, the current study provides several contributions to the role of microaggressions through the framework of SCCT. Further investigation is needed to better understand how racial and gender microaggressions in science influence key constructs of SCCT.

\section{Strengths and Limitations}

This study is not without its limitations. First, the sample included individuals who are still within the science pipeline. Although many participants described experiencing microaggressions or knowledge of those who no longer remain within the science pipeline, their experiences may be distinct from those who have left the sciences. Furthermore, individuals who remain in the sciences may describe microaggressions in a different manner than those who did not persist. For example, some participants described instances of experiencing microaggressions but simultaneously described feeling motivated to persist through the experience. Additional 
research should explore perceptions of microaggressions from individuals who have left the science pipeline.

Another limitation of this sample is that these youth participants represent a unique sample of high school and college students. STEMulate students were recruited to the science support program because of their high academic achievement in high school and the presence of familial support for the program. This limits the generalizability to the broader high school population in general and the Latino population in particular.

Lastly, a limitation of the study is the racial and gender makeup of the sample. Much of the sample is from historically represented identity groups within the sciences (i.e. male or White). Individuals from represented backgrounds may not perceive racial or gender microaggressions to be occurring within the sciences. Furthermore, most participants from underrepresented ethnic backgrounds were STEMulate students, limiting the perceptions of scientists of color from the graduate student and faculty roles. This limits the variability of perceptions of microaggressions occurring within those career development stages.

Despite these limitations, there are several strengths of the present study. While we did not specifically ask about microaggressions, they emerged as a prominent theme within the racial and gender experiences of participants. The qualitative methodology employed allowed for this discovery beyond what the intended interview protocol originally aimed to achieve. Furthermore, we provided nuanced findings, such as the theme of mobility across science contexts, which highlights the role of environmental invalidations among underrepresented groups in the sciences. We add to the present literature on microaggressions within the sciences by providing additional evidence of the influence gender microaggressions, as well as the influence of environmental invalidations in experiences in science settings. 
Another strength of the present study is its examination of perceptions from varying perspectives along the science pipeline. This allowed for a unique understanding of microaggressions across development stages in science education and career development. Namely, this investigation filled a gap in the literature that lacked investigation of samples with high school and college students. Additionally, patterns of microaggressions emerged from the data that may suggest unique experiences of emerging scientists, such as the anticipation of gender and racial microaggressions and how it may inform where individuals choose to attend school or how they may be treated within the science settings. These strengths provide an opportunity to further understand factors impacting participation, well-being, and retention of women and underrepresented ethnic minority groups along the science pipeline.

\section{Conclusions and Future Directions}

The findings from the present study added important contributions to the literature on microaggressions and provided support to prior research on microaggressions within the sciences. While the present study provided novel findings, there is still future research needed to understand the role of microaggressions in the sciences. Specifically, future research should seek to explore perceptions of those who have left the sciences and the role of individual processes to persist in the face of microaggressions.

The present study examined perceptions of racial and gender microaggressions within the sciences. Although all participants reported receiving negative messages and experiencing microaggressions and discrimination from other sources, such as family, society, and media, only microaggressions occurring within science education and careers were examined. For example, all participants, but STEMulate students in particular, provided rich discussion of messages about science from their family or society. However, exploring messages outside of science 
settings was beyond the scope of the current project. Future studies should explore microaggressions and messages occurring about science outside of science settings because such microaggressions may influence individuals' pursuit of science education and careers during critical career development stages.

Future research should also provide further distinctions between the operationalization of microassaults and other forms of subtle discrimination. The findings of this study support that all forms of microaggressions influenced science education and career development. However, differentiation between microassaults and overt racism and sexism requires further explication within the Microaggression Taxonomy. While microassaults provide further support to the plethora of evidence on the detrimental impact of overt discrimination, it should be explored whether they manifest uniquely in comparison to overt racism and sexism. Furthermore, distinction between implicit biases may be necessary as racism and sexism manifest in modern forms. For example, while implicit bias may be more attitudinal in nature, microaggressions may operate as a behavioral manifestation of implicit bias. Additional research is needed to address these differences to further the understanding of experiences of racial and gender microaggressions.

Guided by SCCT, the present study provided important evidence for the negative role of racial and gender microaggressions in science education and career development. However, this is the first study of microaggressions to be guided by this theory. Future research should empirically examine the relation between microaggressions and core components of SCCT. For example, the themes of anticipations of microaggressions and mobility across science contexts suggests microaggressions may influence science-related choice behavior or outcome 
expectations within science. Additional research should examine whether racial and gender microaggressions relate to science-related actions and goals.

The present study supports the existing evidence that racial and gender microaggressions are shared experiences among individuals from underrepresented gender and racial groups in science fields. This study provided three important contributions, including: added evidence of the perceptions of microaggressions among high school students, added empirical evidence of environmental and gender microaggressions, and added evidence of the negative role of microaggressions on career development as described by SCCT. While the present study provided support to the overall literature on microaggressions, future research is needed to explore the role of microaggressions among individuals who have left the science pipeline. The findings of this research can help increase the retention and well-being of underrepresented groups within the sciences. 


\section{References}

Alexander, Q.R. \& Hermann. M.A. (2015). African-American women's experiences in graduate science, technology, engineering, and mathematics education at a predominantly white university: A qualitative investigation. Journal of Diversity in Higher Education, 1-17.

Bandura, A. (1986). Social foundations of thought and action: A social cognitive theory. Englewood Cliffs, N.J.: Prentice-Hall.

Barthelemy, R.S., McCormick, M., \& Henderson, C. (2016). Gender discrimination in physics and astronomy: Graduate student experiences of sexism and microaggressions. Physical Review Physics Education Research, 12, 1-14. DOI:

10.1103/PhysRevPhysEducRes.12.020119

Brown, B.A., Henderson, J.B., Gray, S., Donovan, B., Sullivan, S., Patterson, A., \& Waggstaff, W. (2016). From description to explanation: An empirical exploration of the AfricanAmerican pipeline problem in STEM. Journal of Research in Science Teaching, 53(1), 146-177. doi:10.1002/tea.21249

Cannady, M.A., Greenwald, E., \& Harris, K.N. (2014). Problematizing the STEM pipeline metaphor: Is the STEM pipeline metaphor serving our students and the STEM workforce. Science Education, 98(3), 443-460. DOI 10.1002/sce.21108

Capodilupo, C.M., Nadal, K.L, Corman, L., Hamit, S., Lyons, O.B., \& Weinberg, A. (2010). The manifestation of gender microaggressions. In D.W. Sue (Ed), Microaggressions and Marginality (193-213). Hoboken, N.J.: Wiley.

Charmaz, K. (2006). Constructing grounded theory: A practical guide through qualitative analysis. London: Sage Publications. 
Chaves, A. P., Diemer, M. A., Blustein, D. L., Gallagher, L. A., DeVoy, J. E., Casares, M. T., \&

Perry, J. C. (2004). Conceptions of work: The view from urban youth. Journal of Counseling Psychology, 51, 275.

Chen, X. \& Soldner, M. (2013). STEM attrition: College students' paths into and out of STEM fields. U.S. Department of Education.

Dedoose Version 6.1.18, web application for managing, analyzing, and presenting qualitative and mixed method research data (2015). Los Angeles, CA: SocioCultural Research Consultants, LLC (www.dedoose.com).

Dovidio, J.F. \& Gaertner, S.L. (2000). Aversive racism and selection decisions: 1989 and 1999. Psychological science, 11(4), 315-319.

Economics and Statistics Administration. (2011, July). STEM: Good jobs now and for the future (Issue Brief No. 3-11). Washington, DC: U.S. Department of Commerce.

Fouad, N.A., \& Santana, M.C. (2016). SCCT and underrepresented populations in STEM fields: Moving the needle. Journal of Career Assessment. DOI: 10.1177/1069072716658324

Grossman, J.M. \& Proche, M.V. (2013). Perceived gender and racial/ethnic barriers to STEM success. Urban Education, 49(6), 698-727.

Guzman, F., Trevino, J., Lubuguin, F., \& Aryan, B. (2010). Microaggressions and the pipeline for scholars of color. In D.W. Sue (Ed), Microaggressions and Marginality (145-167). Hoboken, N.J.: Wiley.

Hill, C., Corbett, C., St. Rose, A. (2010). Why so few? Women in science, technology, engineering, and mathematics. Retrieved from American Association of University Women website: http://www.aauw.org/research/why-so-few/ 
Lent, R.W., Brown, S.D., \& Hackett, G. (1994). Toward a unifying social cognitive career theory and academic interest, choice, and performance. Journal of Vocational Behavior, 45, 79122.

Lent, R.W., Brown, S.D., \& Hackett, G. (2000). Contextual supports and barriers to career choice: A social cognitive analysis. Journal of Counseling Psychology, 47(1), 36-49.

Lester, J., Yamanaka, A., \& Struthers, B. (2016). Gender microaggressions and learning environments: The role of physical space in teaching pedagogy and communication. Community College Journal of Research and Practice, 40(11), 909-926. DOI: $10.1080 / 10668926.2015 .1133333$

Lilienfeld, S.O. (2017). Microaggressions: Strong claims, inadequate evidence. Perspectives on Psychological Science, 12(1), 138-169.

Lincoln, Y.S. \& Guba, E.G. (1986). But is it rigorous? Trustworthiness and authenticity in naturalistic evaluation. New Directions for Program Evaluation, 1986: 73-84. doi: $10.1002 /$ ev.1427

McGee, E.O., Thakore, B.K., \& LaBlance, S.S. (2016). The burden of being "model": Racialized experiences of Asian STEM college students. Journal of Diversity in Higher Education, 1-17. http://dx.doi.org/10.1037/dhe0000022

Nadal, K.L. (2009). Gender microaggressions: Implications for mental health. In M. Paludi (Ed.), Women's psychology: Feminism and women's rights worldwide. Santa Barbara, CA: Praeger,

Nadal, K. L., Mazzula, S. L., Rivera, D. P., \& Fuji-Doe, W. (2014). Microaggressions and Latina/o Americans: An analysis of nativity, gender, and ethnicity. Journal of Latina/o Psychology, 2(2), 67-78 
Nadal, K.L., Wong, Y., Griffin, K.E., Davidoff, K., \& Sriken, J., (2014). The adverse impact of racial microaggressions on college students' self-esteem. Journal of College Student Development, 55, 461- 474.

National Science Foundation, National Center for Science and Engineering Statistics. (2015). Women, minorities, and persons with disabilities in science and engineering: 2015 (NSF Special Report 15-311). Retrieved from http://www.nsf.gov/statistics/wmpd/.

National Math and Science Initiative. (2013). STEM Education Statistics. https://www.nms.org/AboutNMSI/TheSTEMCrisis/STEMEducationStatistics.aspx

National Student Clearninghouse. (2015). Science and engineering degree attainment 2004-2014. http://nscresearchcenter.org/snapshotreport-degreeattainment15/

Patton, MQ. (1999). Enhancing the quality and credibility of qualitative analysis. HSR: Health Services Research, 34, 1189-1208Settles, I., Cortina, L., Malley, J., \& Stewart, A. (2006). The climate for women in academic science: The good, the bad, and the changeable. Psychology of Women Quarterly, 30, 47-58.

Pittman, C.T. (2012). Racial Microaggressions: The narratives of African American faculty at a predominately White university. The Journal of Negro Education, 81(1), 82-92.

Rosenbloom, S.R. \& Way, N. (2004). Experiences of discrminiation among African-American, Asian-American, and Latino adolescents in an urban high school. Youth \& Society, 35(4), 420-451. DOI: 10.1177/0044118X03261479

Settles, I.H., Cortina, L.M., Malley, J., \& Stewart, A.J. (2006). The climate for women in academic science: The good, the bad, and the changeable. Psychology of Women Quarterly, 30, 47-58. 
Solorzano, D.G. (1999). Critical race theory, race and gender microaggressions, and the experience of Chicana and Chicano scholars. Qualitative Studies in Education, 1, 121136.

Sue, D.W. (2010). Microaggressions, marginality, and oppression: An introduction. In D.W. Sue (Ed), Microaggressions and Marginality (3-22). Hoboken, N.J.: Wiley.

Sue. D.W. (2010). Taxonomy of microaggressions. In D.W. Sue (Eds), Microaggressions in everyday life: Race, gender, and sexual orientation (21-53). Hoboken, N.J: Wiley.

Sue, D.W. (2017). Microaggressions and "evidence": Empirical or experiential reality. Perspectives on Psychological Science, 12(1), 170-172.

Sue, D. W., \& Capodilupo, C. M. (2008). Racial, gender, and sexual orientation microaggressions: Implications for counseling and psychotherapy. In D. W. Sue \& D. Sue (Eds.), Counseling the culturally diverse: Theory and Practice (5th ed., pp. 105-130). Hoboken, NJ: John Wiley \& Sons.

Sue, D.W., Capodilupo, C.M., Torino, G.C., Bucceri, J.M., Holder, A.M.B., Nadal, K.L., Esquilin, M. (2007). Racial microaggressions in everyday life: Implications for clinical practice. American Psychology Association, 62(4), 271-286).

Trina, M.D.C., Jayasinghe, M.,J., \& Pieper, J.R. (2015). Perceived workplace racial discrimination and its correlates: A meta-analysis. Journal of Organizational Behavior, 36, 491-513. DOI: 10.1002/job.1988

The White House, Office of the Press Secretary. (2009). President Obama launches "Educate to innovate" campaign for excellence in science, technology, engineering \& math (STEM) education [Press release]. Retrieved from https://obamawhitehouse.archives.gov/the- 
press-office/president-obama-launches-educate-innovate-campaign-excellence-science-

technology-en

United States Census Bureau. (2012). U.S. census bureau projections show a slower growing, older more diverse nation a half century from now. Retrieved from: https://www.census.gov/newsroom/releases/archives/population/cb12-243.html

United States Census Bureau. (2015). Quickfacts: United States. Retrieved from: https://www.census.gov/quickfacts/table/PST045216/00 


\section{Appendix A}

Interview Protocol

Recently the National Science Foundation has suggested that it is important to increase the number of women and underrepresented racial/ethnic minority groups in science. We're interested in this topic as well, so I'm going to ask you some questions about the roles of gender and race/ethnicity in science.

1. Would you mind telling me how you identify in terms of gender and race/ethnicity?

2. How do you think being a [insert participant ethnicity here] woman/man has influenced your experience as a scientist?

3. What gender barriers, if any, are there for in pursuing a major or career in science?

4. What barriers, if any, are there for people from racial/ethnic groups that are underrepresented in the sciences in pursuing a major or career in science?

5. What barriers, if any, are there for people of your race/ethnicity in pursuing a major or career in science?

6. Have you experienced explicit harassment or discrimination as a woman/man of your race/ethnicity? If yes, how did you handle the situation?

7. How do expectations of you as a woman/man of your race/ethnicity align with a career in the sciences? Were there any ways in which a science career does not fit those expectations?

8. The STEMulate program targets Latina/o students who are underrepresented in the sciences. What advice would you give to Latino/a high school students about pursuing the sciences? 